\title{
TRANSPORTATION AND ECONOMIC DEVELOPMENT
}

Final Report

Yorgos J. Stephanedes

Department of Civil and Mineral Engineering University of Minnesota

Minneapolis, Minnesota 55455

July 1988 
FORETORD

This research was supported by the Minnesota Department of Transportation. The University research team included the following individuals in alphabetical order:

David Eagle, Department of Civil \& Mineral Engineering and Dept. of Economics Dr. Wilbur Maki, Department of Applied \& Agricultural Economics

Dr. Herbert Mohring, Department of Economics

Dr. Eric Sheppard, Department of Geography

Dr. Yorgos J. Stephanedes, Department of Civil \& Mineral Engineering

The bulk of the research was performed by David Eagle, a Graduate Research Assistant at the Department of Civil \& Mineral Engineering and a $\mathrm{Ph} . \mathrm{D}$ candidate at the Department of Economics, under my direction. Dr. Sheppard provided major assistance in critical periods of the project. Additional work was performed by John Ziotas of the Department of Civil \& Mineral Engineering, and the Minneapolis firm of Regional Econometrics, Inc.

We gratefully acknowledge the help that we received from the following:

Hussein Akhavi, Department of Applied \& Agricultural Economics

Dr. Sant Arora, Department of Industrial Engineering \& Operations Research

Dr. John Borchert, Department of Geography

Dr. Richard Lichty, Department of Economics, Duluth campus

We also appreclate the assistance of the project monitor, other Minnesota DOT staff, the staff of the Regional Development Council in Duluth, the staff of the surveyed forest product and transportation firms, the members of the Regional and State Research Center, the University of Minnesota L.ibraries and Computer Center, as well as numerous other individuals and organizations that made this project possible.

As Principal Investigator of this research project I thank my colleagues for giving me the opportunity to interact with them. To then goes the credit for the successful completion of this work. On the other hand, I stand fully responsible for the views expressed in this report ani all the inevitable errors.

Yorgos J. Stephanedes

Minneapolis

July 1988 
TABLE OF CONTENTS

FOREWORD

page

I. INTRODUCTION

II. BACKGROUND

1. Review of previous work

2. Conceptual framework

III. METHOD

10

IV. RESULTS - PART ONE 16

1. Total employment 16

2. Sector employment

V. RESULTS - PART TWO 22

1. Evaluating criteria for highway project selection 22

2. Highway project selection and simulation of impacts 26

VI. RECOMMENDATIONS 


\section{INTRODUCTION}

States have recently assumed a greater role in facilitating econonic development. This may be the result of a reduction in federal funding or it may reflect an emerging recognition that regional development programs may be more effective when designed locally. A major part of these programs has been shaped by public investment policies that can be directed to easing transportationrelated physical barriers to development. In particular, Departments of Transportation in 36 states explicitly consider regional economic development in highway program selection. The consideration of the economic development criterion rests on the premise that there exists a relationship between transportation investment and the economy. Empirical analysis that has been performed in this area to date, however, has led to little agreement among transportation researchers as to the impact of highway expenditures on economic development.

Historically, transportation has had undeniable effects on the growing economy of the new settlements in this country. The location of communities was often determined by the location of transportation, be it a river or railroad. However, today's mature highway network provides a high degree of accessibility relative to what existed a hundred years ago. Thus, today's highway projects may lack the substantial and lasting economic effects experienced as the country was being developed. No researcher questions the fact that, if there is no transportation infrastructure at all then transportation is necessary for development, simply because development without communication and trade is meaningless. It is in situations where a transportation system already exists that researchers disagree about the efficacy of transportation investment; and 
if there is any agreement at all in this area it seens to be that the more complex and well-connected the initial transportation system is, the harder it is to predict, on the basis of past research, whether transportation improvements will help the local economy. Simllarly, it is hard to predict whether letting the transportation infrastructure deteriorate by cutting back on the expenditures required to adequately maintain the present network will hurt the economy. Since the state of Minnesota certainly has a transportation system that is by and large both well developed and well connected, this result is of some interest.

This report summarizes the results of a project undertaken by a University of Minnesota team for the Minnesota Department of Transportation (Minnesota DOT) to determine the existence and extent of relationships between transportation and economic development (in particular, employment) in Minnesota. The interdisciplinary team was directed by the Department of Civil \& Mineral Engineering and included experts from Civil \& Mineral Engineering, Geography, Economics (both Twin Cities and Duluth campuses), Applied \& Agricultural Economics, Industrial Engineering \& Operations Research, and Regional Economics. 


\section{BACKGROUND}

\section{II.1 Review of previous work}

Regional economic development impacts of highways have been empirically evaluated either directly or indirectly. Such previous work includes largescale economic models in Japan and the U.S. and studies of the impacts of controlled access highways, the most well-known of which were in Connecticut and Pennsylvania as well as the United Kingdom (for a more detailed discussion of these and other references, see the Appendix). The indirect evaluations use large-scale models to simulate the effects of changes in highway infrastructure. This indirect method of estimating regional economic impacts faces several pitfalls related to the large scale of the system and other user assumptions. Consequently, the results of the simulations may differ substantially from what occurs in reality. Large-scale models may be used as a theory of how a certain effect occurs, but they do not in and of themselves demonstrate that the effect exists.

The majority of the direct evaluation studies have used cross-sectional, correlational analysis (i.e., analysis of data from several regions but at the same point in time), although such an analysis is unable to determine the direction of causality. For example, a correlation between highways and development may be due to highways following developnent instead of highways causing development. Time-series analysis (i.e., analysis of data from different points across time), which can distinguish between cause and effect (in the sense that a cause systematically precedes the effect), has only been employed in the current project. 
The inconclusive and occasionally contradictory conclusions on the relationship between transportation and economic development are the result of two major developments. First, previous studies have considered this issue at substantially different geographical scales, ranging from large-scale multistate regional studies on one extreme to small urban land use projects on the other, and based on a wide range of implicit assumptions. There is no reason to believe that the process works in the same manner at all different scales. Second, at the subregional scale of analysis (i.e., county and multi-county up to state scale), which is of interest to us, most previous studies are partial in nature. To avoid the potential for inconsistencies, we have restricted this work to the subregional scale.

\section{2 Conceptual framework}

Although few would quarrel with the conceptual importance of transportation investment to regional development, the actual formulation of transportation investment programs and criteria has posed numerous complications, not to mention serious debate. The traditional view in the literature has been that the improvement of transportation infrastructure is a necessary predecessor to economic development in a region. However, in the last 10 to 15 years this view has come under heavy criticism from a number of directions. Empirical research in a number of countries provided a series of counterexamples which called this view into question. In particular, studies of transportation and economic development plans in the Soviet Union and China as well as of the development of the railroads in the United States pointed out that transportation can be a concurrent or resultant of rather than a predecessor to regional economic 
development. In a similar manner, research into the role of transportation in European and Third World countries also discovered nany instances where the development of transportation into the interior exacerbated rather than decreased economic development differentials between the major cities and rural peripheries of these countries. Furthermore, the complexities of the interdependencies between places in a well integrated spatial economic system (such as in Minnesota) may mean that the effects of transportation improvements are hard to predict and not necessarily beneficial. In summary, transportation can have a positive, neutral or negative effect on development. In addition, the direction of long run impacts may be different to that of short run impacts.

Much of what we know about the role of transportation in affecting the development of a local area (a town or county) stems from our knowledge of how transportation costs affect the profitability of locations for different kinds of activities. Typically, for geographical purposes we divide activities into 3 distinctive types. First, activities that consume large quantities of land, agriculture and forestry being prime examples. Second, activities which do not consume large quantities of land but for which geographical variations in the cost of production are the prime element in choosing locations, such as manufacturing industry. The literature indicates that, in Minnesota, in both of these types of activities, transportation improvements either will not have significant effects or the effects will be less substantial than those resulting from changes in other cost factors. (For more details, including references, see the Appendix.)

The third type of activity includes those for which access to the consumer is vital, such as services provided by the tertiary sector. In Minnesota, any 
effects of transportation improvements on services are likely; to be nore dramatic in competition between service locations than on the overall disposition of consumers to purchase goods, because the state has a good highway net and most services are widely available. In other words, highway investment is more likely to reallocate service employment between different parts of the state than to generate new employment. This statement is based on conclusions drawn from the geography literature and is supported by our analysis of the county employment data, for each sector of the economy and for all counties in Minnesota over the past 19 years (see also Appendix). Further, low order services (such as the corner grocery) in Minnesota are most likely to benefit from transportation improvements as long as they are not too close to the large urban centers. If they are too close, such services may suffer in the long term unless they are located within the dominant centers, (For more details, see the Appendix.)

In summary, the complexities of the interdependencies between places in a well integrated spatial economic system imply that the effects of transportation improvements are complex and hard to predict (this observation is of interest to Minnesota, where the transportation system is by and large both well developed and well connected). However, it has become clear that the best way to empirically evaluate the possible effects of transportation investment on the economy would be to examine situations where transportation investment does seem to temporally precede changes in the local economy. and to determine whether. and in which situations, that impact is likely to be positive, neutral or negative. This is the research direction adopted by this project. 


\section{METHOD}

The past empirical studies have been weak and inconclusive as they have relled on cross-sectional statistical methods that can determine correlations but cannot break those correlations into causal links (i.e., links between variables that determine whether changes in one varlable cause changes in another.) We, therefore, endeavored to take an approach that would address the question of causal linkage more directly than do cross-sectional techniques. In particular, time-series techniques can identify situations in which transportation investment seems to temporally precede or follow changes in the economy. In addition, time-series techniques can determine the extent of the impact, where it exists. At the same time, we were aware that we were probably breaking new ground in this area of research.

We used the time-series techniques to pool (i.e., link together statistically) time-series and cross-sectional data for all 87 Minnesota counties from 1964 to 1982 on state trunk highway construction expenditures and employment (in later research, not funded by this project, we also analyzed the data on income) at the county level. Using these techniques, we analyzed the effect of highway expenditures on employment (and of employment on highway expenditures) with respect to different groupings of counties, as well as the state in total, and for different sectors of the economy. For instance, the first county group is defined as "Regional Center counties" and inludes the counties with a city the size of Mankato (pop.: 28,651) or larger. The Regional Center counties are the 7 counties that are the economic centers of the state: Hennepin (Minneapolis), Ramsey (St. Paul), St. Louis (Duluth), Stearns (St. Cloud), olmstead (Rochester), Blue Earth (Mankato), and Clay (Moorhead) -- see map at end of 
report. These counties are also the economic centers of Minnesota; they employ $2 / 3$ of the workers of the state, earn 718 of the state income and contain approximately half of the state population.

Prior to the analysis, we filtered out the domination (bias) of individual county size as well as changes reflecting regional or national trends, inflation, and other effects that are common to the grouping of counties under study. One result of this filtering is that the analysis now responds to the question, "Does highway investment above (or below) the normal trend of investment in a county influence economic development beyond the normal trend of the economy in that county?" For instance, this analysis can assess a $10 \%$ investment increase in the same fashion it can address a 10 decrease.

We accomplished the above filtering in several ways. First, we defined all variables of an Individual county (such as county expenditures or employment) relative to the county group to which that county belongs. This definition filters out of the analysis any exogenous event (such as inflation, unemployment, federal funding) that may have affected all counties in the group in a similar fashion. Such exogenous events are responsible for the majority of the job growth in a state as recently determined by a Harvard University study that focused on the Massachussetts economy. By defining several different county groupings (such as counties that are regional economic centers, counties whose economy heavily depends on a particular sector -- e.g., agriculture -., border counties, etc.) we have attempted to filter out of the analysis the effects of most major exogenous events that might have systematically influenced our conclusions. Second, we further redefined each variable of the analysis by subtracting the historical average over the study period (e.g., the time average 
over 26 years) so that we can include in the analysis the data from all counties for all the years (e.g., 26 years). Third, we sought to filter out the dominance of large counties, for which the absolute variation of employment and highway expenditures would be greater than in small counties. Specifically, to filter out the effects of county size on data fluctuations, we transformed all variables by redefining them relative to an index that is sensitive to the size of a county, i.e., employment. While the above filtering does not guarantee that we have completely eliminated all possible effects of outside factors on our results, it does ensure that we have substantially reduced the potential influence of the outside factors that we considered to be most important. To be sure, we could extend our filtering process to treat additional factors should such factors be identified.

As the above discussion indicates, classifying the 87 counties in groups based on their characteristics is an essential element of the filtering process. In addition, the classification makes the analysis of the results more meaningful as it allows us to focus on each group of counties separately. In particular, since possible relationships between highway expenditures and economic development would be likely to differ across groups, we develop and evaluate a separate relationship for each group thus making the identification and understanding of possible impacts, by group, easier. We note that, since the county characteristics on which classification is based do not place any geographical restrictions on the classification, the counties that belong to each of the resulting groups are not necessarily adjacent. Nevertheless, the essence of highways is that they connect points and pass through a string of several counties in performing their function. This interconnection would be relevant to our analysis as we could infer by examining our current groupings 
and results. More specifically, our results indicate that highway expenditures Granger-cause (i.e., "cause," as defined by Granger in his concept of "Granger causality", a concept that defines $a$ variable $X$ as "causing" varlable $Y$ if $X$ systematically precedes $Y$ over time) employment increases in Regional Center counties. But these counties depend for their growth, in part, on good connecting links with the "outside world". For instance, although employment may not grow in counties adjacent to the Regional Centers, highway expenditures in these adjacent counties may allow their residents to commute to work in the Regional Centers and thus result in growth in the income of these residents.

Given such intercounty connections, it would be desirable to "relax" the boundaries of county groups so that the connecting function of highways is considered. In other words, it would be desirable to modify the existing "closed" system of each county group so that it becomes an "open" system. Ideally, such treatment would incorporate in the analysis all interactions between any county and any other county in Minnesota that are connected by a major road. Evidently, the number of needed equations could increase exponentially with the number of interactions, and this would impede the identification of statistically significant relationships and the formulation of meaningful conclusions. We could resolve this dilema in three different ways, listed below in order of increasing complexity and beginning with the one that would be easiest to develop and implement:

- When developing the county classification, consider the degree of highway connection between counties in the group.

- Extend the existing model of interrelationships between highways and the economy in each county, by adding terms that reflect the interaction between counties that are connected by major roads. Limit the degree of such interactions so that statistical analysis and conclusions are meaningful.

- Develop a new dynamic formulation that treats each county as an "open" 
system, 1.e., one that allows each county to interact with every other county in the analysis.

Having resolved the above issue using one of the suggested methods, we could employ this analysis to address problems of a local nature. For instance, we could analyze and evaluate the effect of improving a specific trunk highway as long as adequate data were available.

In summary, compared to the methods in the literature, our analytical method is stronger in several ways:

- By employing time-series analysis, where all previous work has depended on cross-sectional (correlational) techniques, we can directly analyze the ways in which a cause systematically precedes an effect over time (e.g., over 26 years). This allows us to make inferences on the direction of a hypothesized relationship between two variables, e.g., distinguish whether highways influence employment or whether employment influences highways - whereas conventional cross-sectional techniques would only indicate a high correlation between the two in both instances and would not be able to distinguish between the two.

- By pooling time-series together with cross-sectional data, we are able to increase our data base by two orders of magnitude compared to a conventional timeseries analysis. This is crucial since 26 years of data (i.e., 26 data elements) would not, by themselves, be sufficient for successful analysis. On the other hand, by pooling the data, we can use 2262 (26 years $\times 87$ counties) elements and this is an adequate size.

- By employing causality tests (Granger-Sims type), we can determine whether a directional influence by a variable (such as highway expenditures) on another (such as employment) also indicates that the first variable (i.e., highways) "causes" (i.e., consistently precedes) the other. We have employed the only existing, stateof-the-art statistical method that can demonstrate the existence of causality. Any other reasoning would have to come from outside statistics (e.g., theory, which, until proven, is open to criticism). Causality tests had never before been applied by transportation researchers in this area. 
- By classifying counties in groups following sinilarities in patterns of characteristics within each group, we can determine the ways in which any relationships we identify may differ across groups. We could further investigate the major causes for the existence and strength of such relationships by naking small modifications to these groups.

- By filtering out of the analysis the irrelevant effects of several exogenous regional and national trends we increase the clarity and significance of our conclusions.

- By employing advanced time-series techniques (such as vector autoregression) we can extend our analysis to all sectors of the economy, concurrently. If desired, we could further investigate the interactions among sectors of the economy as a result of highway inves tment. 


\section{RESULTS - PART ONE}

\section{1 Total employment}

\section{IV.1.1 Influence of transportation on employment}

Regarding total employment (i.e., the summation of employment for all the sectors of the economy), we have strong evidence that highways "cause" (i.e., temporally precede in a systematic manner) long-term economic development in excess of the normal trend in the regional centers of Minnesota, where twothirds of all Minnesotans work and which absorb approximately half of the Minnesota DOT state trunk highway funds. In each of these counties, $\$ 1$ million above the normal expenditures leads to at most 100-140 new jobs, each year, over the next ten years. Of these, a few are created in the second year but most are created in the period between the fifth and the tenth year following the highway expenditures.

There exists no indication of a long-term causal influence of highway expenditures on total employment in the counties that contain the remaining onethird of the workers of Minnesota. For instance, we have no strong evidence that highways influence employment in the counties that are adjacent to the regional centers -- although there exist indications that the effect, if it exists, is likely to be negative, especially outside the Twin Cities Metro Area. We do have some evidence of influence in rural areas (all counties that are not regional centers or adjacent to them) but this evidence is strongest in the short term, i.e. during the period of construction. In addition to construction-related activities, only a small portion of the long term effect 
can occur in this short period; 1.e., there is not sufficlent time for new jobs to be created or lost as a result of the higher travel speeds, heavier loads permitted, etc. (Our later research indicates that highway investment have long term impacts on those rural areas that can use the better roads to improve access of farm products to markets, and access of tourists to the area.)

The finding that improved highways tend to favor employment in regional centers and may hurt employment in areas adjacent to such centers should not be surprising. (To be sure, exogenous events such as inflation, unemployment, federal funding, influence employment changes by affecting a group of counties in a similar fashion. In fact, such exogenous events are responsible for the majority of the job growth in a state as recently determined by a Harvard University study. However, as we pointed out earlier, we have employed filtering methods to filter out such effects with respect to the group of counties under analysis.) In particular, we note that regional centers are also economic centers of the state and, therefore, are most likely to have the economic activity that is necessary for absorbing the highway improvements. On the other hand, the areas adjacent to regional centers tend to depend on these centers for the infrastructure necessary for development; better highways allow area residents to conduct more of their economic activities in the nearby centers. (This phenomenon is not as pronounced in the 5 counties bordering Hennepin and Ramsey.) Further, a comparison of the percentage of people working (66\%) and living (478) in the regional centers strongly suggests that highways are helping the residents of the adjacent counties to get to work as well as provide jobs for them.

The distributional nature of the effects is evident when analyzing the different 
parts of the state. In particular, whlle certain counties are likely to gain from improved roads, others are likely to lose and the statewide effect is not significant; in addition, the statewide effect is very small in size, i.e., over ten years a $10 z$ investment increase would lead to only a 0.018 increase in jobs statewide (otherwise stated, an extra $\$ 1$ million would create an average of only 5-8 new jobs statewide), most due to the spending associated with the construction of the highway. The negligible economic effect of highway funding on a statewide basis indicates that the potential for statewide economic gains could not be a valid argument on which to base decisions for increased highway funding in Minnesota.

IV.1.2 Influence of employment on transportation

We found that the influence of total employment on highway investment is very highly significant statewide, both in the short and in the long term. In addition, the sensitivity of highway investment relative to changes in employment is substantial, i.e. an increase of jobs by a given percentage (say, 108) above the trend attracts an additional investment statewide of almost double the size in percentage terms -- approximately 188 over ten years (otherwise stated, an extra 100 jobs attract an extra $\$ 28,500$. ) Following detailed accounting of this effect and the stated influence of highways on employment, the calculations indicate that, at current funding levels and employment, approximately one of every 60 new jobs in regional centers is created by Minnesota DOT state trunk highway funds.

The influence of employment on highway investment is most significant, both in the short and in the long term (but especially in the short term), in rural 
areas. Thus it appears that the short-term economic velt being of the rural counties influences state hishway investment policy the most.

\section{2 Sector employment}

Although our analysis concluded that, in general, highway expenditures do not cause total employment above the normal trend of economy, highway expenditures may cause the employment within a specific economic sector. (The sectors of the economy examined are, manufacturing, wholesale, retail, service, financeinsurance-real estate, transportation-communication-public utilities, construction, and agriculture.) In particular, we have strong evidence of favorable long-term effects of highway improvements in the wholesale sector of rural counties. Lacking substantial nearby competition, firms in this sector may benefit since their products become more accessible to potential customers, i.e. their sales area increases. Firms may also benefit as transportation cost is an important cost component for their products that are perishable or expensive to transport in comparison to their delivered price.

(We note that our later research also indicates strong evidence of favorable small-scale long-term effects of highway improvements in the service sector of the rural counties that have a strong natural-resource economic base. To be sure, the density of the highway system in these counties of north Minnesota is low with lakes and forests impeding communication in Minnesota and Canada. Better roads have the potential to increase service employment - - a sector that represents approximately one-third of the economy in these counties, higher than in most other regions in the state -. by facilitating tourism in the area. Since the total number of jobs in those counties is not very high, even a small- 
scale effect can be important to the local economy.)

However, we also have some evidence of adverse effects on agriculture cash receipts in counties that border the regional centers, and this is in agreement with the transportation geography literature. More specifically, the literature has argued to good effect that locations which are close to the fringe of a city may be subject to reduced agricultural activity since farmers expect to sell the land for urban development, and thus are less likely to invest in its upkeep for agricultural purposes. This would be more likely to occur around the Twin Cities metropolitan area, in locations where there are no regulations prohibiting further development.

Conclusions regarding the relationship between highways and economic development greatly depend on the way in which development is defined. For instance, findings from our ongoing work indicate that, while improved roads may hurt the employment in certain counties, the same road improvements may support increases in household income in those counties. These findings are in agreement with Census data which indicate that 66 of the state's population works in the Regional Center counties while only 478 lives there, implying that about 198 of the state's population commute on highways to their jobs in Regional Center counties from other counties.

Summarizing the above findings, our analysis indicates that:

- The effect of economic development on highway funding is much greater than the effect of highway funding on economic development.

- The effect of the economy on highway expenditures is positive, i.e. the Minnesota DOT reacts to changes in 
econemic conditions by providine more funding te erese in uhich the economy is srouling. (However, our later research indicates that, in several rural areas, the effect of the economy on highway expenditures is negative, 1.e., the DOT attempts to stimulate their faultering economy by providing more funding; such funding is not as effective in terms of job creation, as the "reactive" type of funding administered in the rest of the counties.)

- For the regions that employ two thirds of Minnesota workers, the Regional Center counties, the effect of hlghway expendltures on the economy is posftive. The effect is also positive in certain rural areas that either have a strong natural resource base (tourism) or can benefit from improved access of their farm products to markets.

A summary of the important long term interactions between highway expenditures and employment is found in Tables 1 and 2 . In the Tables, positive and negative signs indicate the sign of the effect from the time-series equations; percentages indicate the level of significance from the causality tests. In interpreting the findings, consistent sign patterns from the time-series equations are as important as results from causality tests.

Table 1. Long-term effects of highway on employment by sector

Total Serv Ret Whol MnfC FIRE TCPU Agri

\begin{tabular}{|c|c|c|c|c|c|c|c|c|}
\hline State & + & + & + & + & + & + & + & - \\
\hline Reg Ctr & +18 & +108 & +18 & + & + & + & + & \\
\hline Next $R C$ & - & & & & & & & -58 \\
\hline Urban & + & + & + & + & + & + & + & \\
\hline Next U & - & - & - & - & - & - & & - \\
\hline Rural & +108 & & & 18 & & & & \\
\hline
\end{tabular}

Table 2. Long-term effects of employment by sector on highway

\begin{tabular}{|c|c|c|c|c|c|c|c|c|}
\hline State & +58 & + & + & + & + & + & + & + \\
\hline $\operatorname{Reg}$ Ctr & + & + & - & + & + & + & + & - \\
\hline Next RC & + & + & + & + & & +18 & + & +58 \\
\hline Urban & + & + & + & + & + & + & + & + \\
\hline Next U & & & - & - & & - & + & + \\
\hline Rural & +58 & + & + & - & & & + & \\
\hline
\end{tabular}

Additional understanding of the role of economic indicators in highway funding decisions can be gained by analyzing the highway progran selection process. We have performed such an analysis and have developed a cost/benefit methodology to aid the highway programming decisions .- with an application to spring load restrictions and the forest industry in Northeast Minnesota. 


\section{RESULTS - PART TWO}

\section{V.1 Evaluating criteria for highway project selection}

\section{V.1.1 Introduction}

This analysis addresses the question, "What is the relationship (if any) between highway project funding decisions by the Minnesota DOT and specific indicators, including indicators that the Minnesota DOT uses?" While the analysis was specifically requested by the Minnesota DOT, it is particularly weak because of the relative scarcity of data. Existing data on specific indicators as well as funding decisions are not sufficient for detailed time-series analysis but can only allow cross-sectional analysis, i.e., exactly the type of analysis we strongly criticized in our earlier discussion. Therefore, all results in this section are correlative, i.e. they simply indicate whether there is a relation between $X$ and $Y$ without specifying whether $X$ precedes $Y$ or whether $Y$ precedes $X$. For instance, let us assume that we find a high correlation between the project selection recommendation by the District and the Minnesota DOT funding decision; this could imply that either or both of the following hold, a) Minnesota DOT listens to the District or b) the District "learns" from past Minnesota DOT decisions -- cross-sectional analysis cannot distinguish between the two effects.

\section{V.1.2 1985 project selection - - to fund or not to fund}

We begin by analyzing the data from the 1985 decisions the Minnesota DOT made regarding selection of projects to fund, including Major Construction and 
Reconstruction projects for 1990 and 1991, and Reconditioning and Resurfacing for 1987 and 1988. This analysis determines the najor factors that are correlated with the funding decision, i.e. the decision "to fund or not to fund" a candidate project in any of the above 4 categories; the factors include the selection criteria ("point system") now followed by the Minnesota DOT. (For more details on the Minnesota DOT selection criteria see the Appendix.) The major conclusions from this analysis indicate the following:

- The 1985 data indicate that the actual relationship between Minnesota DOT decisions and major criteria it uses to make these decisions is generally close to the relationship stated by the Minnesota DOT. This is particularly true for projects in the Reconstruction category, where the discrepancy is almost nil.

- Of all the point components, Cost Efficiency (CE) and Sufficiency Rating (SR) points are most significant in Major Construction and Reconstruction, while Condition Rating (CR) is most significant in Reconditioning and Resurfacing. Goods Movements (GM) and PM (Peak Month) points are not significant.

- The funding decision is very sensitive to FC (Functional Classification) points in Major Construction and Reconstruction, to $C R$ points in Reconditioning and Resurfacing, and to $S R$ in Major Construction and Reconstruction. Any reporting inaccuracies would be highly magnified, 2 to 5 times in these cases. As an example, a discrepancy of half a point in $C R$ can shift the probability of funding for a typical Resurfacing project by 35 points on a 0-100 probability scale. Therefore, extreme care is needed, especially when recording $C R$ and $S R$, where a measurement error can easily arise.

- The priority each District assigns to the projects it submits for consideration is the most consistently significant factor in the funding decision. The contribution of this factor to the decision often equals that of all other factors combined. Further, the funding decision is sensitive to the District priority; if the District raises its priority rating by a point (scale 110), the probability of funding is raised by approximately 10 points (scale $0-100$ ).

ADT is a significant factor in Reconditioning and Resurfacing but is almost irrelevant for Major Construction decisions. However, ADT-related factors, e.g. Commercial 
$A D T$ (in Major Construction) and ADT divided by cost/mile (In all cases) are often more significant than ADT. The sensitivity of funding to ADT is highest in Reconditioning and lowest in Major Construction. For instance, on a $0-100$ point probability scale, a 1000-car ADT increase can raise the funding probability 2-6 points in Reconditioning, and 1-2 points in Reconstruction and Resurfacing; however, in Major Construction a 10,000 car increase would hardly make a difference in funding.

\section{V.1.3 1972-1985 project funding .. how much to fund}

The 1985 data set was unique in that it contained both the projects that were funded and those that were not. As a result, it was possible to determine the significance and the weight of the factors that may have helped shape the outcome of the "fund/no fund" decision. Unfortunately, the Minnesota DOT data for prior years refer only to the projects that were funded. As a result, we can only use those data to determine the significance of factors that may influence the amount of funding. More precisely, the question we seek to answer must be modified to, "Given that a project is selected for funding, what is the relationship (if any) between the amount of funding and specific indicators, including indicators that the Minnesota DOT uses?" Because of data limitations, this analysis considers all 4 project categories together.

Remarkably, the relationship between ADT and funding per mile has remained stable since 1972. As expected, this relationship is positive, i.e. higher ADT corresponds to higher funding per mile. In particular, for every 10-percent ADT increment on a highway to be funded, we can expect a 6-8 percent corresponding increment in funds per mile for that project on the average, after adjusting for inflation. 
The relationship between CR (all CR data are from 1980) and funding is negative as expected, 1.e. higher $C R$ corresponds to lower funding per mile. In particular, for every 10-percent increment in $C R$, we can expect a 30-60 percent corresponding decrease in funds per mile for a typical project. Because of the extremely high sensitivity of funding to $C R$, a half-point error in measuring $C R$ could result in a funding difference of up to $\$ 450,000$ for a typical 5-mile project.

The data indicate a positive relationship between funding and either income or employment. This implies that more highway funds become available to areas of higher income and/or employment. This was generally expected for two reasons. First, a positive relationship has already been found between funding/mile and both ADT and commercial ADT, economic indicators that are substantially correlated with income (correlation between ADT and income $-52-66 \%$ ) and are already included in the project selection process. The second reason is that, in most counties, a positive relationship has been found in our time-series analysis presented earlier - - indicating a "reactive" mode of DOT policies to changes in the economy. To be sure, the results from that analysis are far more detailed and reliable (they were able to also identify cases in which the DOT policy is stimulative, not reactive) than the exaggerated numbers our correlative analysis produces; therefore, we shall not cite any of the latter.

Nevertheless we can use the results from the time series analysis to interpret the findings of the cross-sectional analysis. In particular, since the timeseries results indicate that, statewide, the interaction between highways and the economy is significant only in the direction of economy influencing highways, we interpret the cross-sectional results as supporting the view that 
economic indicators such as the District priority rating, ADT, employment, and income (in that order) influence highway investment decisions in a significant and substantial manner, 1.e., in most cases, better economic conditions attract, with a lag, increased highway funding.

\section{V.2 Highway project selection and simulation of project impacts}

\section{V.2.1 Highway project selection based on long term benefit-cost analysis}

In this section we are concerned with the ways expected benefits and costs (including any possible direct and indirect economic impacts) of highway projects can be considered for highway project selection. In particular, we develop an algorithm for obtaining a road development progran that optimizes the relationship of costs and benefits of the projects in that program while meeting a specified budget constraint. Although we concentrate our analysis in selecting projects that deal with changing the weight carrying limits on the state highways, our methodology is formulated in a general manner so that it could be applied to other types of projects and, therefore, could be used to aid the highway project selection process of the Minnesota DOT.

Because a regional highway network serves a considerable number of plants and markets and consists of a large number of links, the benefits resulting from improving a single link of the network are almost never inmediately realized. Alternatively, the network links could be upgraded in sets so that the lowest construction costs result in the maximum realizable benefits. In the case of weight limits, a benefit is realized only when the minimum load limit along a travel route is raised, and it is this special feature (constraint) that makes 
the problem interesting.

We apply our analysis to transportation benefit and cost data from the forest industries and the highway system in northeast Minnesota. In this application, changes in weight restrictions, in the direction of upgrading and expanding year-round 10 -ton state routes, are expected to affect the transport cost per mile and the direct yearly net benefits. For instance, assuming constant demand and supply between origins and destinations, the direct benefits depend on the number of saved trips, the transportation unit cost, the length of trips and the time period in which the benefits occur. If the shipping patterns of forest industry products remain consistent with previous shipping patterns and the number of shipments is not reduced by the closing of forest plants, then the impact of upgrading a forest product route may be significant.

The realized economic net benefits of road investments are quantified through the transportation cost reductions. However, the net benefits vary among the industries of an economic sector because the method of transportation cost payments varies from one industry to another. In the forest industry, for instance, an examination of alternative payment structures is necessary because changes in factors affecting the transportation cost determine different schemes of benefits for the shippers and the freight carrying companies. Some shippers pay the freight carriers a flat rate for the movement of their products. Others, contracting with independent truckers, pay by the loaded miles, by the running mile, or by the loaded miles with an additional hourly rate for time spent at the truck terminal. Shippers who lease trucks pay according to a lease agreement. In the first payment alternative, transportation cost reductions are a benefit to the carriers, while in the rest of cases the benefits are enjoyed 
to a larger extent by the shippers. We have analyzed all major alternative payment structures and have used the raw data to draw conclusions that apply to all industries included in this work.

The algorithm developed here solves the problem of combining the maximum realizable economic benefits, resulting from the alleviation of weight restrictions or other road improvements, with the minimal incurred construction costs, expended for the upgrading of the network links. Both benefits and costs are amortized over the time horizon appropriate for each project. The objective is maximization of the total net benefit summed over all customers and all commodities subject to the total available budget over the planning horizon. The algorithm considers two maintenance policy alternatives regarding the route capacity of the network:

(a) Road ( $i, j$ ) from origin $i$ to destination $j$ is upgraded to carry heavier loads. Alternatively,

(b) Road ( $i, j)$ is not upgraded but is still used for heavier loads. This would lead to a reduced expected life and an increase in the maintenance costs.

The set $U$ of all feasible project combinations includes upgrading combinations that lead to the same final outcome but are accomplished in a different sequence. For instance, a 9-ton road may be upgraded to 10-ton directly; alternatively (and this would be considered a different project in $U$ ), the 9-ton road may be partially improved at first, e.g., to 10 -ton for 10 months. To be sure, the cost of upgrading a highway in steps is higher than making the complete improvement at once.

The nature of the relationship between the total optimal benefit $Z$ and the available budget $W$ is illustrated in Figure 1 . In general, the set $U$ initially 


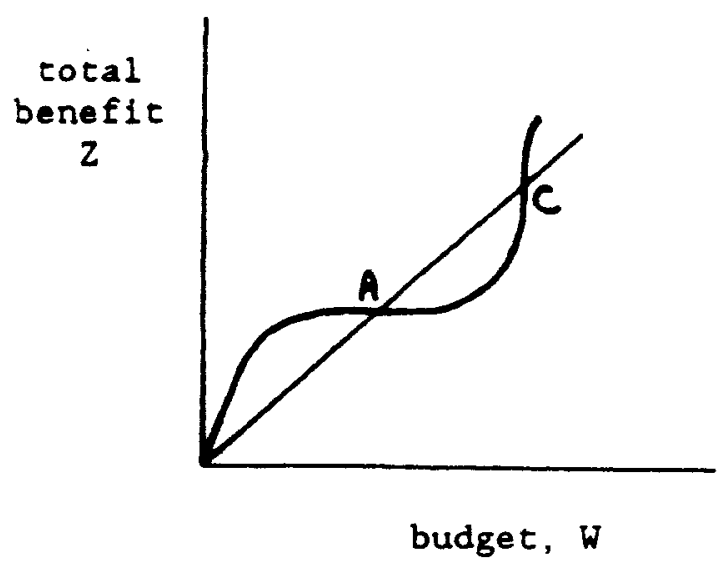

Fig. la Beginning with $B / C>1$

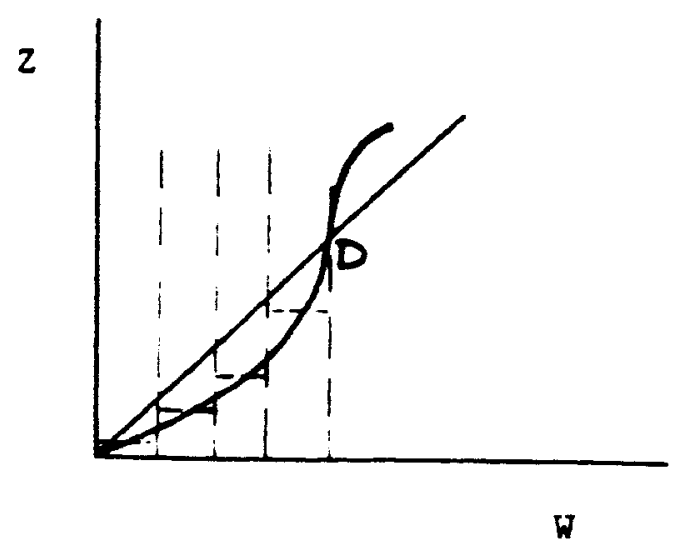

Fig. 1b Beginning with $B / C<1$

Figure 1. Total optimal benefit as a function of available budget

may contain one or more small projects, the completion (upgrading) of which leads to immediate completion (upgrading) of one or more complete routes. If such projects are present in $U$, the curve of Fig. la begins with a $B / C$ ratio greater than one. If, on the other hand, no such project exists in $U$ initially, the rate of accumulation of the total benefit $Z$ is slow and the curve begins below the breakeven $(B / C=1)$ line as Fig. Ib indicates. As more road segments are completed, the benefit accumulation rate accelerates and the curve of Fig. Ib may again cross the breakeven line as it enters a range where $B / C>1$ at some stage (point D). Towards the end, when most important routes in the network have been upgraded, the rate of increase of $Z$ slows down again.

\section{v.2.2 Case study in Northeast Minnesota}

The objective of the case study is to analyze the economic viability of upgrading the spring weight restrictions on the state highways of northeast Minnesota. In particular, the case study focuses on evaluating the network upgrading on the basis of realized net benefits from the paper and waferboard 
product industries of that region. Direct benefits would accrue if the network upgrading reduced transportation costs and, thus, made the final production cost of the above forest products more competitive in the nation's markets. These industries could, then, increase the production capacity of their plants and, in time, their export market share in the national and international markets.

While transportation cost is an important factor in the final cost of the voluminous forest products, organized cost and shipment data do not exist or are incomplete - therefore, we had to collect the necessary data and thus create a complete database for our analysis. In particular, the difficulties associated with the collection of reliable data and data confidentiality are often cited as the two major reasons for the lack of complete data. In order to obtain a more complete database on paper and waferboard product shipments, we conducted a survey in northeast Minnesota in 1985. The survey sought information on shipment origins and destinations, cost structure, tonnage, modal split, shipment value, trip duration, etc. for the nine leading woodpulp mills in the area. The paper and waferboard producers belonged to the following companies: Potlatch, Blandin, Northwood Panelboard, Boise Cascade, Superwood, Conwed, Diamond International, and Great Lakes Forest Products. A summary of relevant data from these producers is presented in Tables 3 and 4.

In addition to the information summarized in Tables 3 and 4 , the responses to our survey indicated that the transportation cost is an important component of the final price of paper and waferboard, especially for shipments outside Minnesota. No surveyed company disclosed product demand data at the customer, town or city level. As a result all our demand data are at the state level. We expanded the above database with data related to the principal highways the 
Table 3. Active pulpwood mills and waferboard plants in northeast Minnesota by location and capacity as of 1982

$\begin{array}{lll}\text { Company } & \text { Location } & \text { Capacity } \\ \text { Woodpulp Mills } & & \text { (tons/24 hrs) } \\ \text { Producer X } & \text { Grand Rapids } & 300 \\ \text { Producer Y } & \text { International Falls } & 920 \\ \text { Producer Z } & \text { Cloquet } & 475 \\ \text { Producer T } & \text { Bemidji } & 100 \\ \text { Producer U } & \text { Duluth } & 350 \\ \text { Producer V } & \text { Cloquet } & 50 \\ & & \\ \text { Waferboard Plants } & & \\ & & 270000 \\ \text { Producer A } & \text { Grand Rapids } & 160000 \\ \text { Producer B } & \text { Bemidji } & 150000 \\ \text { Producer C } & \text { Bemidji } & 150000 \\ \text { Producer D } & \text { Cook } & \end{array}$

Table 4. Data Summary of Forest Product Producers in NE Minnesota*

\begin{tabular}{|c|c|c|c|c|c|c|c|}
\hline Company & $\begin{array}{l}\text { max distance } \\
\text { between plant } \\
\text { and market } \\
\text { (miles) }\end{array}$ & $\begin{array}{l}\text { max distance } \\
\text { between plant } \\
\text { and market } \\
\text { by truck } \\
\text { (miles) }\end{array}$ & \multicolumn{2}{|c|}{$\begin{array}{l}\text { transp cost } \\
(\$ / \mathrm{m} i)\end{array}$} & $\begin{array}{l}\text { Shipment } \\
\text { flat-bed } \\
\text { truck }\end{array}$ & $\begin{array}{l}\text { size (shor } \\
\text { irregular } \\
\text { common } \\
\text { carriers }\end{array}$ & $\begin{array}{l}\text { it ton } \\
\text { rail }\end{array}$ \\
\hline 1 & 1800 & $\overline{\mathrm{U}}$ & 1.2 & 2.5 & 23 & 23 & na \\
\hline 2 & 2100 & $\mathrm{U}$ & $1.1-1.4$ & $2.2-5.5$ & na & na & 51 \\
\hline 3 & 48 states & 800 & 1.2 & 3.5 & 23 & na & 75 \\
\hline 4 & 48 states & 800 & 1.2 & 3.5 & 23 & na & 75 \\
\hline 5 & 48 states & $\mathrm{U}$ & $1.1-1.3$ & na & na & 23 & na \\
\hline 6 & 48 states & $\mathrm{U}$ & $1.1-1.2$ & na & 23 & 18 & na \\
\hline 7 & 700 & 700 & NA & 1.0 & na & 22 & 62 \\
\hline
\end{tabular}

\footnotetext{
* - for confidentiality purposes, not all producers are listed.

$U$ - unlimited; depends on market conditions and order size.

na = not applicable; mode not used.

$\mathrm{NA}=$ not available
} 
forest industries use in northeast Minnesota. We used these data, provided by the Minnesota Department of Transportation, to develop the layout of the relevant highway network, illustrated in Figure 2. The Minnesota DOT classifies these highways in three load categories, i.e.,
a) E - category: 9-ton roads operated as 10-ton in the 3 winter months,
b) F - category: 9-ton roads operated as 10-ton for 10 months, and
c) G - category: 10-ton roads year-round.

Using the above information, the principal highways of NE Minnesota were segmented into links by load category and estimated remaining life .. see Table 5. Our algorithm was then used to analyze these highways with the help of a personal computer. The computer code accepts the road length and remaining life of highways, and the number of truckloads between origins and destinations as inputs. The output is a prioritization of the available projects subject to a budget constraint. The project prioritization results are based on the assumption that the realizable project benefit per truck load is approximately 3 short tons, i.e., the difference between the currently allowed 73820 pounds GVW and the desirable 80000 pounds GVW. No effects were considered that relate to possible truck detouring or plant closing because of road deterioration.

Based on the algorithm, only the segment of Trunk Highway 33 (TH 33), connecting Interstate 35 (I-35) with Cloquet (see Figure 3) has a benefit/cost ratio greater than 1. From all candidate upgrading projects considered, the following were selected in order of priority (the selection is based on $B / C$ ratios that are calculated from the data received from the industry and the Minnesota DOT; these data, as is the case with all data, are subject to errors): 


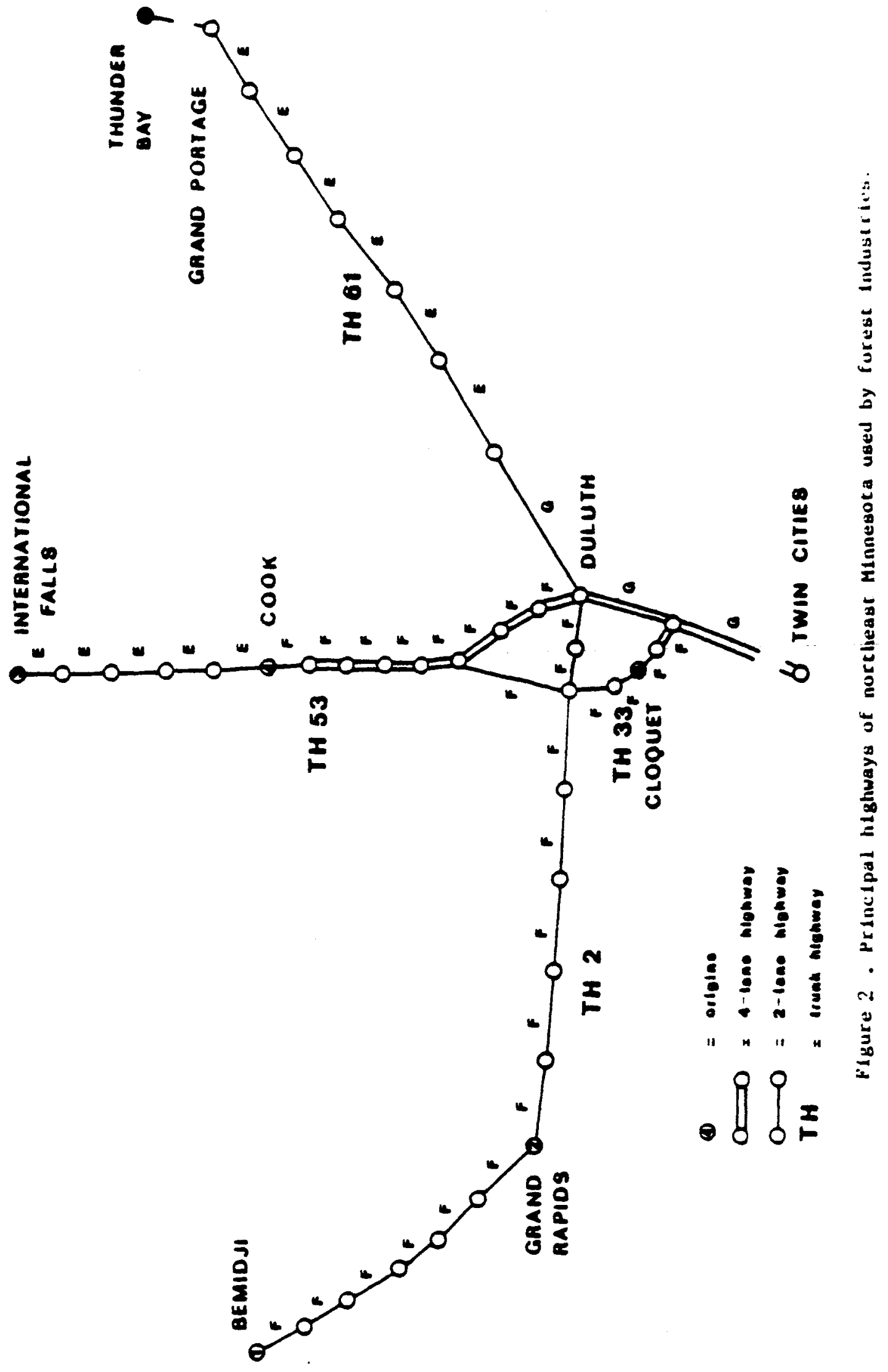


1. TH 33, from I-35 to Cloquet; upgrade to 10-ton road year round.

2. TH 33, from Cloquet to TH 2 ; and

TH 2, from TH 33 to Grand Rapids; to 10-ton year round.

3. TH 53, from Cook to International Falls; to 10-ton for 10 months.

4. TH 2, from Grand Rapids to Bemidji; to 10-ton year round.

5. TH 61, from Two Harbors to U.S. border; to 10-ton for 10 months or year round.

6. TH 33, from $\mathrm{TH} 2$ to $\mathrm{TH} 53$, and

TH 53, from TH 33 to International Falls; to 10-ton year round.

All prioritized projects are placed on the Minnesota map of Figure 3 . The cumulative B/C ratio of the projects (see Figure 4) illustrates the lack of attractiveness of all projects once the first one is selected. To be sure, the low cumulative $B / C$ is mainly the result of considering the direct benefits accruing to only one customer, i.e., the forest industry. Nevertheless, the forest industry is a major user of the NE Minnesota highways and this implies a high likelihood that the above projects would not be attractive, even if additional users were considered. [The Minnesota DOT has recently alleviated weight restrictions on TH 2 based on highway engineering criteria (deflection tests) and is considering upgrading Th 33 from I-35 to Cloquet.]

The above analysis does not consider the indirect cost of not tending to deteriorating highways in a timely fashion. For instance, roads of low quality may cause truck detours and higher transportation cost. When the cost crosses a certain threshold, that the industry considers unacceptable, that industry may relocate; similarly, new industry may not be attracted. Further, the analysis does not consider any rerouting that may take place following partial upgrading of the network. However, the centralized nature of the NE Minnesota network substantially reduces the possibility for such rerouting. 


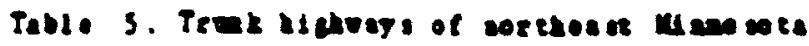
ared if torest indertios

\begin{tabular}{|c|c|c|c|c|c|c|}
\hline \multirow{2}{*}{$\begin{array}{l}T=02 \\
\operatorname{lich}_{2}=5 \\
(\mathrm{~T})\end{array}$} & \multirow[b]{2}{*}{ Node } & \multicolumn{2}{|c|}{2 Leses } & \multicolumn{2}{|c|}{4 Lasos } & \multirow[b]{2}{*}{ Catesory } \\
\hline & & M11 eese & $\begin{array}{c}\text { Renigine } \\
\text { Lafe }\end{array}$ & $M_{i l} \operatorname{eese}$ & $\begin{array}{l}\text { Rearesas } \\
\text { Lise }\end{array}$ & \\
\hline \multirow[t]{7}{*}{33} & $E-31$ & & & & & \\
\hline & & $\begin{array}{l}2.69 \\
1.03\end{array}$ & 25 & 2.65 & 4 & 8 \\
\hline & Sloner & & & & & \\
\hline & & 3.73 & 9 & & & 8 \\
\hline & & 4.10 & 24 & & & $\boldsymbol{F}$ \\
\hline & $D$ & 8.25 & & & & $F$ \\
\hline & X. 51 & & & & & \\
\hline \multirow[t]{14}{*}{2} & Dents & & & & & \\
\hline & & $\begin{array}{l}7.01 \\
6.77\end{array}$ & $\begin{array}{l}20 \\
35\end{array}$ & & & $\begin{array}{l}p \\
P\end{array}$ \\
\hline & D.19. & & & & & \\
\hline & & 1.94 & 12 & & & $\mathbf{P}$ \\
\hline & D.33 & & & & & \\
\hline & & $\begin{array}{l}12.62 \\
25.65\end{array}$ & $\begin{array}{l}20 \\
17\end{array}$ & & & 8 \\
\hline & & 7.38 & 23 & & & P \\
\hline & & 22.24 & 3 & & & 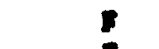 \\
\hline & & 2.85 & 9 & & & $P$ \\
\hline & Gernd & & & & & \\
\hline & & 9.9 & 18 & & & 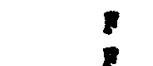 \\
\hline & & $\begin{array}{r}0.35 \\
12.35\end{array}$ & 38 & & & 8 \\
\hline & & 6.95 & 14 & & & 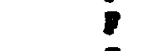 \\
\hline & & $\begin{array}{l}27.35 \\
22.8\end{array}$ & $\begin{array}{l}29 \\
24\end{array}$ & & & $\frac{P}{P}$ \\
\hline
\end{tabular}

53 Dente

\section{Bnidu}

Dint

7.0

2.91

6
10
21

$$
\begin{aligned}
& 7.25 \\
& 9.94 \\
& 1.36
\end{aligned}
$$

$\begin{array}{rr}6 & 8 \\ 10 & 8 \\ 21 & 5\end{array}$

I. 33

$\begin{array}{rrr}1.67 & 21 & 12.03 \\ 16.97 & 7 & 8.54 \\ 16.03 & 4 & 16.09 \\ 11.89 & 18 & 9.86\end{array}$

$\begin{array}{rr}21 & 5 \\ 7 & 8 \\ 18 & 5 \\ 18 & 8\end{array}$

Coot

22.22

19

17.26

18.07

3.25

Interntioned

Pnil:

61 Delnet

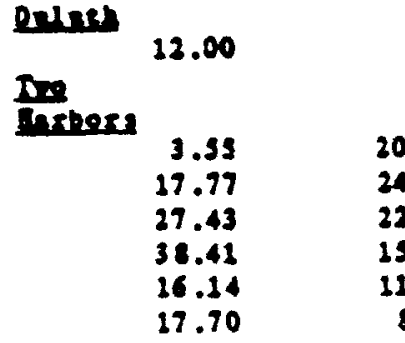

$\theta$

D.s.

20
24
22
15
11
8

8
8
8
8 


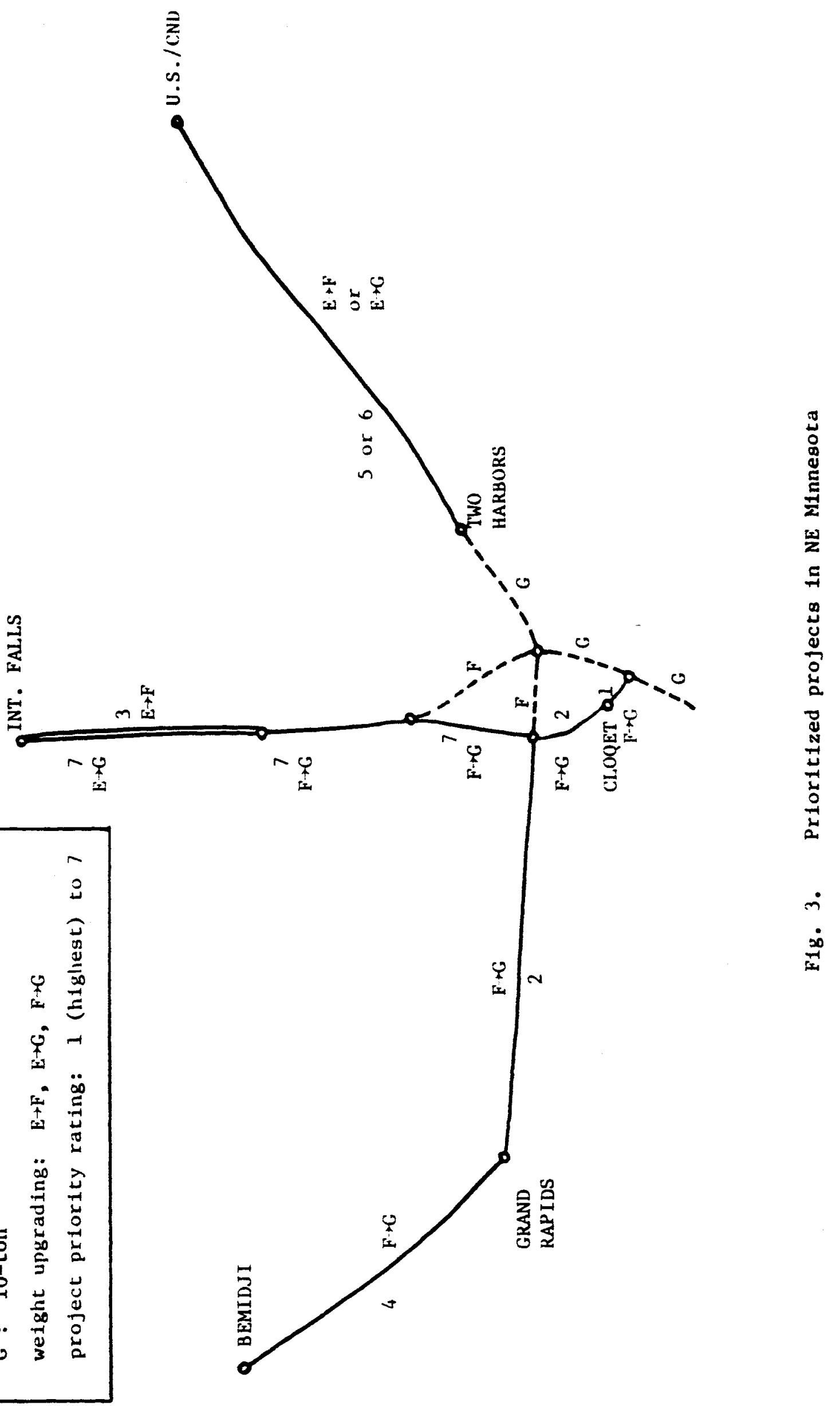




\begin{tabular}{|l|l|}
\hline \multicolumn{2}{|c|}{ Selected } \\
\hline Rank & EB/EC \\
\hline 1 & 1.3 \\
2 & 0.23 \\
3 & 0.13 \\
4 & 0.09 \\
5 & 0.03 \\
6 & 0.03 \\
7 & 0.03 \\
\hline
\end{tabular}

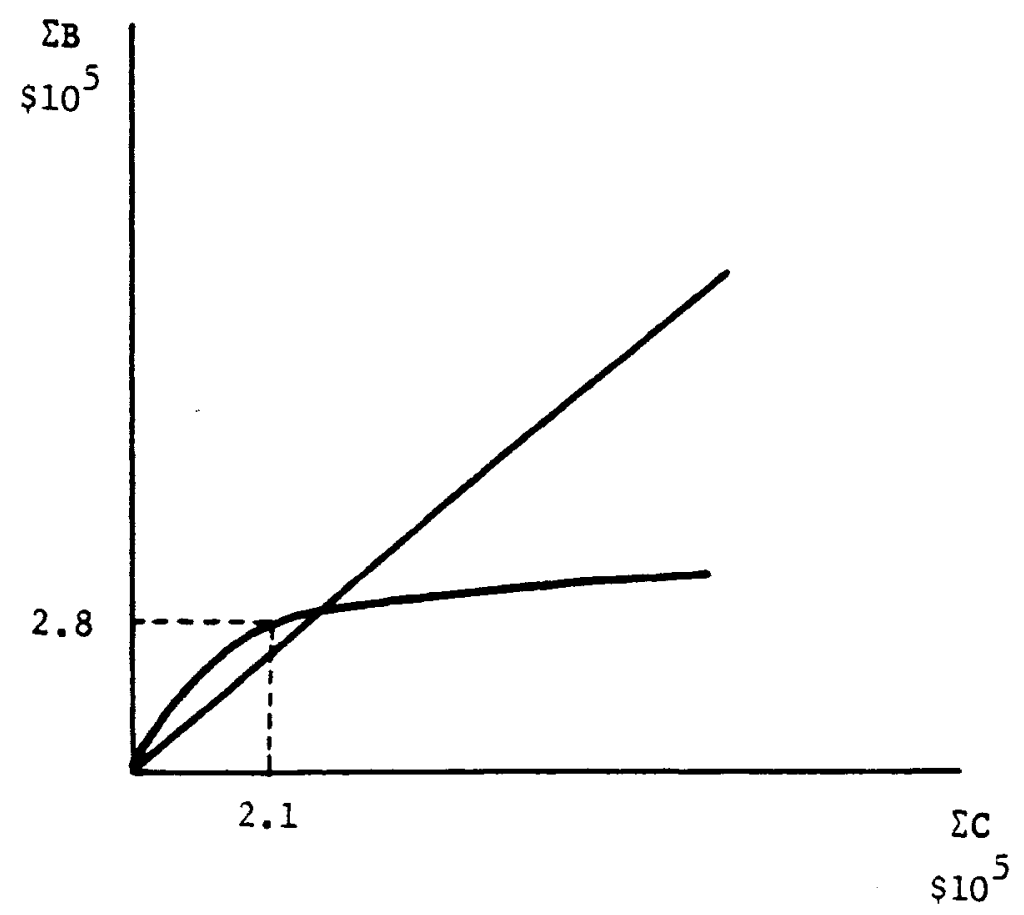

Fig. 4. Cumulative $B / C$ for the selected projects in NE Minnesota 
As part of the case study, we have also used an alternative indirect analytical method to assess the economic effects of a transportation policy in Northeast Minnesota. In particular, we assess the possible economic effects on the local forest industry of increasing all spring load restrictions in NE Minnesota to 10 tons year round. To accomplish this, we use the large-scale Input-Output SIMIAB economic simulation model appropriately modified to handle this regional problem. While SIMLAB does not determine whether the spring load restriction is economically efficient, it does determine all the effects - - both primary (direct) and multiplier (indirect) of the restrictions. The benefit-cost analysis described above can then be performed based on this information.

The timber industry sectors considered include logging, sawmills, particle board, other wood products, pulp and paper. For our base-case analysis we use the status quo in 1977. At that time, some roads were restricted to 7 tons for part of the year and most allowed 10 -ton loads except in spring when they were restricted to 9 tons. From our interviews with the major local companies, it is evident that the increase in weight carrying capacity will enable most companies to increase their truckload shipments while maintaining the same transport cost, since they now must ship a given number of truckloads at a higher cost. In this analysis, we assume that all the cost savings are passed onto the purchaser.

For the regional economy as a whole, a 18 decrease in transportation cost can lead to only a small increase in gross output and earnings that should not be expected to exceed 0.028 . (However, individual sectors can do better and can reach as high as 0.17 for the particle board sector.) The total increase in regional output with upgraded weight limits is estimated as a function of industry market share. For instance, if we assume that the lower transportation 
cost results in a relatively small increase of the market share of the industry, then regional output is expected to increase by $\$ 70,000$; similarly, if we assumed a market share increase ten times as large, the corresponding output increase would be $\$ 700,000$. (To be sure, the benefits would probably increase if all small forest companies were also included in the analysis.) Tax revenues from this increase could support upgrading a total highway length of between 5 and 50 miles based on current tax and cost estimates, where the low end of the scale supports the earlier benefit/cost analysis conclusions that pointed to the need for upgrading the 5-mile stretch of road from I-35 to cloquet.

One of the prime findings of this avenue of investigation was that application of this method to other industries and other areas in Minnesota is feasible. (This finding does not apply to the use of the Input-Output simulation model, which is not operational for all regions of Minnesota.) An additional factor that should be considered when applying this method to other industries and other areas in Minnesota is the time value of the products being shipped. While timber products have some inventory value if not shipped during the weightrestricted season, products such as grain, not only have inventory value but can also have significant price fluctuations. If grain is to be shipped during the weight-limited season, the entire annual harvest may have to be shipped inefficiently. Upgrading the roadway would, then, have much more substantial results than in the case of the timber-related industry of Northeast Minnesota. 


\section{RECOMMENDATIONS}

1. The 7 counties that employ two-thirds of Minnesotans and constitute the regional economic centers of the state (Hennepin, Ramsey, St. Louis, Olmstead, Stearns, Blue Earth, and Clay) can demonstrate significant and sizeable long-term employment improvements following increase of transportation investment (as evidenced by the Granger-sims causality test, the structural plots, the vector autoregressions and the elasticities). This finding is particularly relevant for the state economy in view of the fact that the Regional Center counties earn 718 of the state income, contain approximately half the state population, and absorb nearly half the Minnesota DOT trunk highway funds (source: Minnesota DOT data.) If government policy is to promote jobs in the economic centers, better transportation can help. (Natural-resource base counties in north Minnesota can also use better transportation to improve their service economy.)

2. The counties that border the 7 economic centers may demonstrate a worsening job climate, especially in agriculture, with improved roads, especially in the 5 centers away from the Twin Cities (as evidenced by the vector autoregressions, the structural plots and the elasticities). However, highways that improve commuting may alleviate some of the hardships of an economic slowdown. If highway improvements enable workers to commute more easily to the nearby centers of economic vitality, income in the border areas may increase (as evidenced by our ongoing work) although employment will be transferred to the centers. Nevertheless, the transfer of employment from the adjacent counties to 
the centers is likely to attract new businesses to those centers and away from the adjacent counties in the long term (as suggested in the literature and by our previous work for the U.S.DOT). If government policy is to improve the economy in the areas adjacent to the economic centers, government should clarify which aspect of the economy it wishes to improve using transportation investment: income may improve but jobs will suffer, To be sure, it could be correctly argued that creation of jobs is significant even if they are not in the same county as that in which the worker lives. For instance, it would seem possible that some of the jobs created in the regional center counties may be jobs that otherwise would have been lost to the entire area (i.e., regional center plus adjacent counties) if the jobs in the regional centers had not been there. However, since no additional jobs are created statewide, this argument would lead to the conclusion that most of the "lost" jobs would have been gained by the rural areas of the state, not by other states.

3. An economic center can use better highways to stimulate its employment; however, some of this employment improvement may occur at the expense of its neighboring counties (as evidenced by the vector autoregressions, structural plots and elasticities). If government policy is to improve employment in all of Minnesota. this cannot be accomplished using the transportation investment tool alone (note, however, that our method could also be employed to estimate the expected effects of other types of state expenditures on economic development); any effects improved transportation may have are relative rather than absolute, e.g. regional center policy makers should be 
aware of the neqative impacts the inproved highways may have on their neighbors, of course, the relative or distributional nature of certain impacts may well be socially and politically desirable. For instance, even though increased highway funding in rural areas may have a small benefit/cost ratio in terms of direct dollar benefits and costs, the funding may provide sufficient support to stabilize a declining town and this social effect may be hard to include in a conventional benefit/cost analysis. Even in such a case, however, care should be taken that the increased highway funding does not result in draining the local economy while the closest large urban area gains (as would happen, for instance, if the improved transportation attracted new industries and services to the urban area; made industries and services of the smaller town to relocate to the urban area; made products and services of the small town to lose in competition to lower-priced products and services of the urban area; made consolidations of services, e.g., banking, educational, religious services, in favor of the urban area necessary.)

4. Strong evidence of favorable long-term employment effects of highway improvements in rural areas (i.e., areas not in the Regional Center or Next-to-Regional-Center counties) was found only for the wholesale sector. However, this long-term effect does not last long, probably not more than 8 years following the highway expenditures (as evidenced by the causality test, the vector autoregression and the structural plot). (Strong evidence of favorable long-term effects was also found in rural areas that either have a strong natural resource base, e.g., tourism, or can benefit from improved access of their farm products to 
markets; although such effects would involve few jobs, they could still be important to the local economy.) Favorable effects in other sectors of the rural areas were found only in the short term, i.e. during construction, and most would be construction-related. Therefore, if government policy is to stimulate employment in rural areas, it can accomplish this during the construction of highways. If policy is to achieve long-term improvements, government can improve transportation to achieve this in the wholesale and service sectors: In all other sectors, transportation improvements alone would not be sufficient and would have to be accompanied by additional development pollcies.

5. Highway funding alone cannot stimulate the Minnesota agriculture (as evidenced by the causality tests, the vector autoregressions and the structural plots, and as already discussed in \#4 above).

6. The current Minnesota DOT project selection process is very highly responsive to the recommendations of the individual districts. The data and the significance tests indicate that district recommendation (reflecting, among other factors, current economic conditions) contributes to the process as much as all other selection factors combined. Therefore, there is no need to use additional economic criteria as long as the Minnesota DOT plans to continue to place such a substantial weight on the district recommendation. To be sure, there exist certain limitations in generalizing this conclusion as it has been drawn from the only available data, i.e. the data on the 1985 decisions on major construction and reconstruction projects for 1990 and 1991, and reconditioning and resurfacing for 1987 and 1988 . 
Nevertheless, we have indications that 1985 was a fairly typical year in the project selection process.

7. Our time-series analysis indicates that the Minnesota DOT is highly responsive to the economic (employment) conditions of Minnesota in two ways: First, in most cases the DOT plays a strongly passive, reactive role in state and regional economic development by increasing highway investment where the economy is improving -. a role that is largely effective. Second, in certain rural counties the DOT plays a stimulative role by providing more funding as their economy is faultering - a role that is, for the most part, ineffective. In particular, although the evidence indicates that increased highway investment is most effective in favorably influencing the economy of the regional centers of the state and of certain natural-resource based rural counties, it is the economic (employment) conditions of the rural areas that exert the most significant influence on Minnesota DOT highway funding decisions. It can be inferred that, unless the state's development priorities are to be changed, inclusion of additional economic criteria in the Minnesota DOT highway project selection process is not needed.

8. If the state's priorities are that the economies of the regional centers should not be improved at the expense of the outlying economies. the evidence indicates no need to use additional economic indicators as criteria in highway programming. The political climate in Minnesota, with a thriving economy in the economic centers and a depressed economy in many areas of Greater Minnesota, is to encourage 
economic development outside the centers. Our analysis indicates that any attempt to further improve the employment of the centers by improving transportation may also have adverse employment effects on their neighbors. To be sure, such adverse effects would be tempered by the income increase of the residents in the areas adjacent to the economic centers who can use the improved roads to commute to the centers - these commuters represent 198 of the state's population (as pointed out elsewhere, this observation is also supported by results from our ongoing work).

9. While including economic indicators in highway programming to stimulate the economy is not justified. the use of additional economic indicators such as employment and income may significantly improve the Minnesota DOT forecasts of future ADT levels as our regression analysis and correlation results indicate. (Our previous reports indicate -. see Appendix for details -. that ADT is highly correlated with both employment and income.) Our review of Minnesota DOT's programming selection procedures revealed the importance of accurate ADT forecasts for reconditioning and resurfacing projects. However, these forecasts are usually only extrapolations of past trends. The forecasts can be improved by using time-series techniques such as the ones used here.

10. Minnesota Dor should optimize the uniformity and consistency in measuring condition and sufficiency ratings. Highway project selection and funding decisions are extremely sensitive to $C R$ and $S R$ measurements (as evidenced by our regression analysis and significance tests); small recording errors may have a substantial effect in project ratings. 


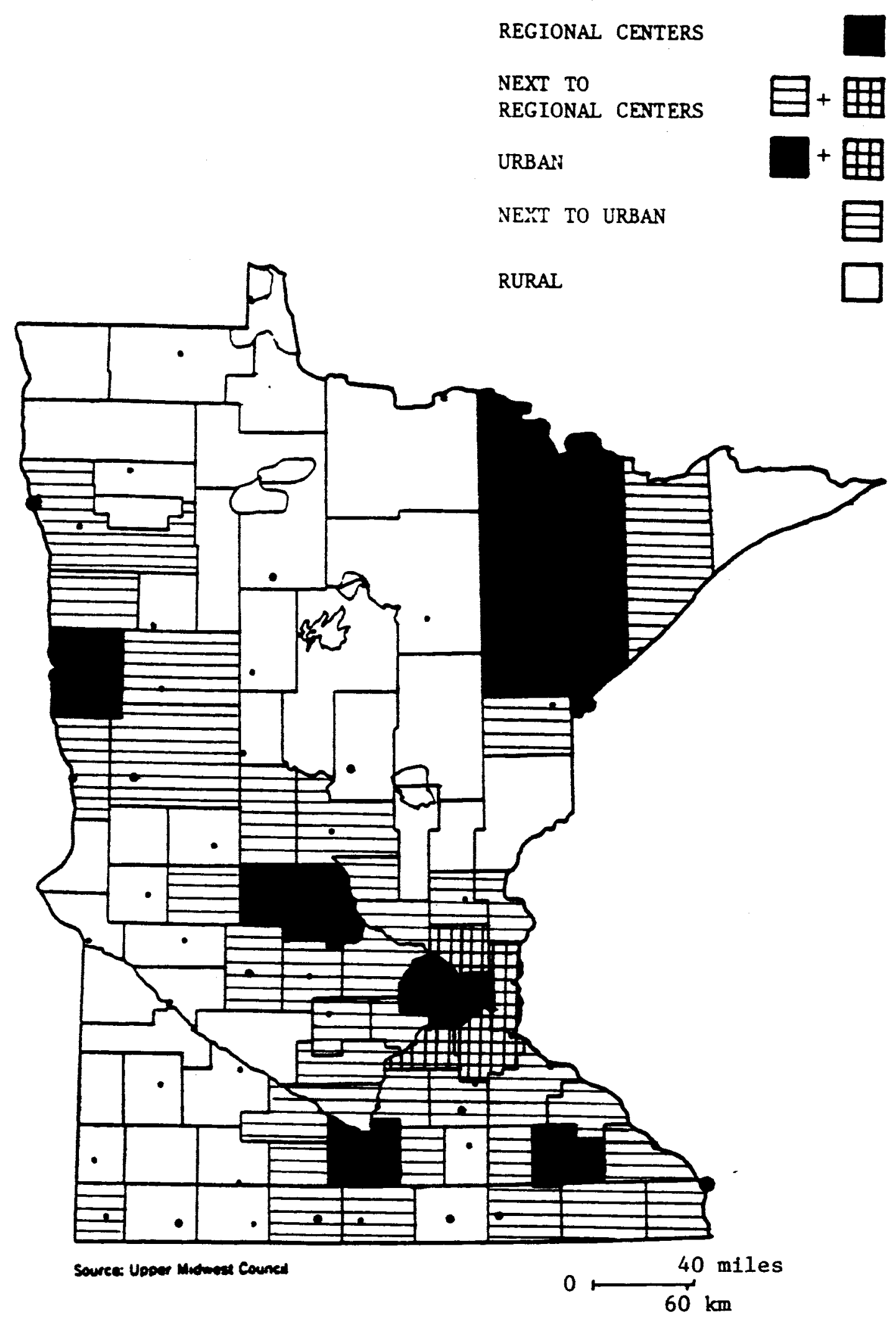

FIGURE 5 . County Groupings 



\section{TRANSPORTATION AND ECONOMIC DEVELOPMENT}

Final Report

Volume II

Yorgos J. Stephanedes

Department of Civil and Mineral Engineering University of Minnesota

Minneapolis, Minnesota 55455

May 1989 


\section{FOREWORD}

This research was supported by the Minnesota Department of Transportation. The University research team included the following individuals in alphabetical order:

David Eagle, Department of Civil \& Mineral Engineering and Dept. of Economics Dr. Wilbur Maki, Department of Agricultural \& Applied Economics

Dr. Herbert Mohring, Department of Economics

Dr. Eric Sheppard, Department of Geography

Dr. Yorgos J. Stephanedes, Department of Civil \& Mineral Engineering

The bulk of the research was performed by David Eagle, a Graduate Research Assistant at the Department of Civil \& Mineral Engineering under my direction and a Ph.D candidate at the Department of Economics. Dr. Sheppard provided major assistance in critical periods of the project. Additional work was performed by John Ziotas and Vijaya Kumar of the Department of Civil \& Mineral Engineering, and Hussein Akhavi of the Department of Applied \& Agricultural Economics.

We gratefully acknowledge the help that we received from the following:

Dr. Russell Adams, Department of Geography

Mr. Steve Alderson, Transp. Progr. Manager, Metropolitan Council, Twin Cities

Dr. Sant Arora, Department of Industrial Engineering \& Operations Research

Dr. John Borchert, Department of Geography

Dr. Will Craig, Asst. Dir., Center of Urban \& Regional Affairs

Dr. David Forkenbrock, Civil/Envir. Engrg. \& Dir., Public Policy Ctr., U.of Iowa

Dr. Jerry Fruin, Department of Agricultural \& Applied Economics

Dr. Lewis Hendricks, Forest Products, Agricultural Extension Service

Dr. Richard Lichty, Department of Economics, Duluth campus

Dr. Glenn Nelson, Department of Agricultural \& Applied Economics

Mr. Dan Salomone, Dir., Research Off., Department of Revenue, State of Minnesota

Dr. Christopher Sims, Department of Economics

We also appreciate the assistance of the project monitor, other Minnesota DOT staff, the staff of the Regional Development Council in Duluth, the staff of the surveyed forest product and transportation firms, the members of the Regional and State Research Center, the University of Minnesota Libraries and Computer Center, as well as numerous other individuals and organizations that made this project possible.

As Principal Investigator of this research project I thank my colleagues for giving me the opportunity to interact with them. To them goes the credit for the successful completion of this work. On the other hand, I stand fully responsible for the views expressed in this report and all the inevitable errors.

Yorgos J. Stephanedes

Minneapolis

May 1989 
TABLE OF CONTENTS - VOLUME II

page

FOREWORD 2

I. INTRODUCTION 4

II. BACKGROUND $\quad 6$

1. Review of previous work 6

2. Conceptual framework 7

$\begin{array}{ll}\text { III. METHOD } & 10\end{array}$

$\begin{array}{ll}\text { IV. RESULTS - PART ONE } & 18\end{array}$

1. Total employment 18

2. Sector employment 21

V. RESULTS - PART TWO 24

1. Evaluating criteria for highway project selection 24

2. Highway project selection and simulation of impacts 28

VI. RECOMMENDATIONS 42 


\section{INTRODUCTION}

States have recently assumed a greater role in facilitating economic development. This may be the result of a reduction in federal funding or it may reflect an emerging recognition that regional development programs may be more effective when designed locally. A major part of these programs has been shaped by public investment policies that can be directed to easing transportationrelated physical barriers to development. In particular, Departments of Transportation in 36 states explicitly consider regional economic development in highway program selection. The consideration of the economic development criterion rests on the premise that there exists a relationship between transportation investment and the economy. Empirical analysis that has been performed in this area to date, however, has led to little agreement among transportation researchers as to the impact of highway expenditures on economic development.

Historically, transportation has had undeniable effects on the growing economy of the new settlements in this country. The location of communities was often determined by the location of transportation, be it a river or railroad. However, today's mature highway network provides a high degree of accessibility relative to what existed a hundred years ago. Thus, today's highway projects may lack the substantial and lasting economic effects experienced as the country was being developed. No researcher questions the fact that, if there is no transportation infrastructure at all then transportation is necessary for development, simply because development without communication and trade is meaningless. It is in situations where a transportation system already exists that researchers disagree about the efficacy of transportation investment; and 
if there is any agreement at all in this area it seems to be that the more complex and well-connected the initial transportation system is, the harder it is to predict, on the basis of past research, whether transportation improvements will help the local economy. Similarly, it is hard to predict whether letting the transportation infrastructure deteriorate by cutting back on the expenditures required to adequately maintain the present network will hurt the economy. This result is of particular interest to Minnesota, a state with a transportation system that is both well developed and well connected.

This report summarizes the results of a project undertaken by a University of Minnesota team for the Minnesota Department of Transportation (Minnesota DOT) to determine the existence and extent of relationships between transportation and economic development (in particular, employment) in Minnesota. The interdisciplinary team was directed by the Department of Civil \& Mineral Engineering and included experts from Civil \& Mineral Engineering, Geography, Economics (both Twin Cities and Duluth campuses), Applied \& Agricultural Economics, Industrial Engineering \& Operations Research, and Regional Economics. 


\section{BACKGROUND}

\section{II.1 Review of previous work}

Regional economic development impacts of highways have been empirically evaluated either directly or indirectly. Such previous work includes largescale economic models in Japan and the U.S. and studies of the impacts of controlled access highways, the most well-known of which were in Connecticut and Pennsylvania as well as the United Kingdom (for a more detailed discussion of these and other references, see the Appendix). The indirect evaluations use large-scale models to simulate the effects of changes in highway infrastructure. This indirect method of estimating regional economic impacts faces several pitfalls related to the large scale of the system and other user assumptions. Consequently, the results of the simulations may differ substantially from what occurs in reality. Large-scale models may be used as a theory of how a certain effect occurs, but they do not in and of themselves demonstrate that the effect exists.

The majority of the direct evaluation studies have used cross-sectional, correlational analysis (i.e., based on data from several regions but at the same point in time), although such an analysis is unable to determine the direction of causality. For example, a correlation between highways and development may be due to highways following development instead of highways causing development. Time-series analysis (i.e., analysis of data from different points across time), which can come substantially closer to distinguishing between cause and effect (in the sense that a cause systematically precedes the effect), has only been employed in the current project. 
The inconclusive and occasionally contradictory conclusions on the relationship between transportation and economic development are the result of two major developments. First, previous studies have considered this issue at substantially different geographical scales, ranging from large-scale multistate regional studies on one extreme to small urban land use projects on the other, and based on a wide range of implicit assumptions. There is no reason to believe that the process works in the same manner at all different scales. Second, at the subregional scale of analysis (i.e., county and multi-county up to state scale), which is of interest to us, most previous studies are partial in nature. To avoid the potential for inconsistencies, we have restricted this work to the subregional scale.

\section{2 Conceptual framework}

Although few would quarrel with the conceptual importance of transportation investment to regional development, the actual formulation of transportation investment programs and criteria has posed numerous complications, and led to serious debate. The traditional view in the literature has been that the improvement of transportation infrastructure is a necessary predecessor to economic development in a region. However, in the last 10 to 15 years this view has come under heavy criticism from a number of directions. Empirical research in a number of countries provided a series of counterexamples which called this view into question. In particular, studies of transportation and economic development plans in the Soviet Union and China as well as of the development of the railroads in the United States pointed out that transportation can be a concurrent or resultant of rather than a predecessor to regional economic development. In a similar manner, research into the role of transportation in 
European and Third World countries also discovered many instances in which the development of transportation into the interior exacerbated rather than reduced economic development differentials between the major cities and rural regions of these countries. Furthermore, the complexities of the interdependencies between places in a well integrated spatial economic system (such as in Minnesota) may mean that the effects of transportation improvements are hard to predict and not necessarily beneficial. In summary, transportation can have a positive, neutral or negative effect on development. In addition, the direction of long run impacts may be different to that of short run impacts.

Much of what we know about the role of transportation in affecting the development of a local area (a town or county) stems from our knowledge of how transportation costs affect the profitability of locations for different kinds of activities. Typically, for geographical purposes we divide activities into 3 distinctive types. First, activities that consume large quantities of land, agriculture and forestry being prime examples. Second, activities which do not consume large quantities of land but for which geographical variations in the cost of production are the prime element in choosing locations, such as manufacturing industry. The literature indicates that, in Minnesota, in both types of activities, transportation improvements either will not have significant effects or the effects will be less substantial than those resulting from changes in other cost factors. (For more details, including references, see the Appendix.)

The third type of activity includes those for which access to the consumer is vital, such as services provided by the tertiary sector. In Minnesota, any effects of transportation improvements on services are likely to be more 
dramatic in competition between service locations than on the overall disposition of consumers to purchase goods, because the state has a good highway net and most services are widely avallable. In other words, highway investment is more likely to reallocate service employment between different parts of the state than to generate new employment. This statement is based on conclusions drawn from the geography literature and is supported by our analysis of the county employment data, for each sector of the economy and for all counties in Minnesota over the past 19 years (see Appendix). Further, low order services (such as the corner grocery) in Minnesota are most likely to benefit from transportation improvements as long as they are not too close to the large urban centers. If they are too close, such services may suffer in the long term unless they are located within the dominant centers. (For more details, see the Appendix.)

In summary, the complexities of the interdependencies between places in a well integrated spatial economic system imply that the effects of transportation improvements are complex and hard to predict -. this observation is of interest to Minnesota, where the transportation system is well developed and well connected. However, it has become clear that the best way to empirically evaluate the possible effects of transportation investment on the economy would be to examine situations where transportation investment does seem to temporally precede changes in the local economy, and to determine whether and in which situations, that impact is likely to be positive, neutral or negative. This is the research direction adopted by this project. 


\section{METHOD}

The past empirical studies have been weak and inconclusive as they have relied on cross-sectional statistical methods that can determine correlations but cannot break those correlations into causal links (i.e., links between variables that determine whether changes in one variable cause changes in another.) We, therefore, endeavored to take an approach that would address the question of causal linkage more directly than do cross-sectional techniques. In particular, time-series techniques can identify situations in which transportation investment seems to temporally precede or follow changes in the economy. In addition, time-series techniques can estimate the extent of the impact, where it exists. At the same time, we were aware that we were probably breaking new ground in the application of these techniques to this area of research.

We used the time-series techniques to pool (i.e., link together statistically) time-series and cross-sectional data for all 87 Minnesota counties from 1956 to 1982 on state trunk highway construction expenditures and employment (in later research, not funded by this project, we also analyzed the data on income) at the county level. Pooling of the data increased the number of data elements from 26 to 2262 ( 26 yrs $\times 87$ counties) and made this analysis possible. (To be sure, the strength of the conclusions from the time-series analysis would have benefited from data on additional types of highway projects, and from periods shorter than a year; however, such detailed data are not available.) Using these techniques, we analyzed the effect of highway expenditures on employment (and of employment on highway expenditures) with respect to different groupings of counties, as well as the state in total, and for different sectors of the economy. For instance, the first county group is defined as "Regional Center 
counties" and inludes the counties with a city the size of Mankato (pop.: 28,651) or larger. The Regional Center counties are the 7 counties that are the economic centers of the state: Hennepin (Minneapolis), Ramsey (St. Paul), St. Louis (Duluth), Stearns (St. Cloud), Olmstead (Rochester), Blue Earth (Mankato), and Clay (Moorhead) - see map at end of report. These counties employ $2 / 3$ of the workers of the state, earn 718 of the state income and contain approximately half of the state population.

Prior to the analysis, we filtered out the domination (bias) of individual county size as well as changes reflecting regional or national trends, inflation, and other effects that are common to the grouping of counties under study. One result of this filtering is that the analysis now responds to the question, "Does highway investment above (or below) the normal trend of investment in a county influence economic development beyond the normal trend of the economy in that county?" For instance, this analysis can assess a $10 \%$ investment increase in the same fashion it can address a $10 \%$ decrease.

We accomplished the above filtering in several ways. First, we defined all variables of an individual county (such as county expenditures or employment) relative to the county group to which that county belongs. This definition filters out of the analysis any exogenous event (such as inflation, unemployment, federal funding) that may have affected all counties in the group in a similar fashion. Such exogenous events are responsible for the majority of the job growth in a state as recently determined by a Harvard University study that focused on the Massachussetts economy. By defining several different county groupings (such as counties that are regional economic centers, counties whose economy heavily depends on a particular sector - e.g., agriculture - , 
border counties, etc.) we have attempted to filter out of the analysis the effects of most major exogenous events that might have systematically influenced our conclusions. Second, we further redefined each variable of the analysis by subtracting the historical average over the study period (e.g., the time average over 26 years) so that we can include in the analysis the data from all counties for all the years (e.g., 26 years). Third, we sought to filter out the dominance of large counties, for which the absolute variation of employment and highway expenditures would be greater than in small counties. Specifically, to filter out the effects of county size on data fluctuations, we transformed all variables by redefining them relative to an index that is sensitive to the size of a county, i.e., employment. While the above filtering does not guarantee that we have eliminated all possible effects of outside factors on our results, it does ensure that we have substantially reduced the potential influence of the outside factors that we considered to be most important. To be sure, we could extend our filtering process to treat additional factors should such factors be identified.

Following filtering, we made use of time-series analysis of the data, enhanced with the employment of causality tests (Granger-Sims type). These tests aided us in inferring whether a directional influence by a variable (such as highway expenditures) on another (such as employment) also indicates that the first variable (i.e., highways) "causes" (i.e., consistently precedes) the other. To be sure, we employed causality analysis with caution, fully aware of its limitations. For instance, we were aware that lacking data on additional variables (such as inflation, unemployment) that could have "caused" the dependent variables under analysis, the causal specifications could suffer from specification error. While inclusion of additional explanatory variables is 
certainly the most desirable solution, we sought to address this issue by employing the extensive filtering process as described above. Further, we did not employ causality tests as the basis for model specifications as such tests can be ambiguous in identifying relationships between variables. Instead, we relied, to a large extent, on consistent results from basic time-series analysis (vector autoregressions) while employing causality analysis to reinforce our view regarding lack of causality when two variables seemed to be irrelevant. This is in agreement with recent economic literature indicating that causality tests perform well in rejecting causality when two events are known to be irrelevant.

The literature and our experience suggest that, in most cases, causality is an overly strict test. When employed with properly pretreated data, the test is unlikely to indicate two variables are causally related if they actually are irrelevant. In addition, in our analysis any such indication of causality had to pass two more tests 1.e., (a) careful examination of the time-series behavior of the data as revealed by the vector autoregression plots; and (b) a theoretical or empirical explanation. Further, we note that the strictness of the Granger-Sims causality test has been known to lead to situations where no causality is found although one would be expected from theoretical or empirical considerations. Knowing this, we used the consistent behavior of the timeseries analysis, when such behavior was in agreement with strong theoretical or empirical arguments, to indicate that causality exists even in cases in which the causality test was negative. Overall, our analysis is certainly imperfect but where it may have erred this has most likely been on the conservative side. In other words, there may exist additional causalities between variables, which strict application of our tools - - causality tests, direct examination of time- 
series plots, theoretical and empirical expectations .. may have missed.

As the above discussion indicates, classifying the 87 counties in groups based on their characteristics is an essential element of the filtering process. In addition, the classification makes the analysis of the time-series results more meaningful as it allows us to focus on each group of counties separately. In particular, since possible relationships between highway expenditures and economic development would be likely to differ across groups, we develop and evaluate a separate relationship for each group thus making the identification and understanding of possible impacts, by group, easier. We note that, since the county characteristics on which classification is based do not place any geographical restrictions on the classification, the counties that belong to each of the resulting groups are not necessarily adjacent. Nevertheless, the essence of highways is that they connect points and pass through a string of several counties in performing their function. This interconnection would be relevant to our analysis as we could infer by examining our current groupings and results. More specifically, our results indicate that highway expenditures Granger-cause (as defined by Granger, variable $X$ "causes" variable $Y$ if $X$ systematically precedes $Y$ over time thus being able to explain $Y$ 's variation better than could be explained by examining $\mathrm{Y}^{\prime} \mathrm{s}$ history alone) employment increases in Regional Center counties. But these counties depend for their growth, in part, on good connecting links with the "outside world". For instance, although employment may not grow in counties adjacent to the Regional Centers, highway expenditures in these adjacent counties may allow their residents to commute to work in the Regional Centers and thus result in growth in the income of these residents. 
Given such intercounty connections, it would be desirable to "relax" the boundaries of county groups so that the connecting function of highways is considered. In other words, it would be desirable to modify the existing "closed" system of each county group so that it becomes an "open" system. Ideally, such treatment would incorporate in the analysis all interactions between any county and any other county in Minnesota that are connected by a major road. Evidently, the number of needed equations could increase exponentially with the number of interactions, and this would impede the identification of statistically significant relationships and the formulation of meaningful conclusions. We could resolve this dilemma in three different ways, listed below in order of increasing complexity and beginning with the one that would be easiest to develop and implement:

- When developing the county classification, consider the degree of highway connection between counties in the group.

- Extend the existing model of interrelationships between highways and the economy in each county, by adding terms that reflect the interaction between counties that are connected by major roads. Limit the degree of such interactions so that statistical analysis and conclusions are meaningful.

- Develop a new dynamic formulation that treats each county as an "open" system i.e., one that allows each county to interact with every other county in the analysis.

Having resolved the above issue using one of the suggested methods, we could employ this analysis to address problems of a local nature. For instance, we could analyze and evaluate the effect of improving a specific trunk highway as long as adequate data were available.

In summary, despite the limitations mentioned above, compared to the methods in the literature, our analytical method is stronger in several ways: 
- By employing time-series analysis, where previous work has depended on cross-sectional (correlational) techniques, we can directly analyze the ways in which one activity systematically precedes another over time (e.g., over 26 years). This allows us to make inferences on the direction of a hypothesized relationship between two variables, e.g., whether highways influence employment or whether employment influences highways -- whereas conventional cross-sectional techniques would only indicate a high correlation between the two in both instances and would not be able to distinguish between the two.

By pooling time-series together with cross-sectional data, we are able to increase our data base by two orders of magnitude compared to conventional time-series analysis. This is crucial since 26 years of data (i.e., 26 data elements) would not be sufficient for successful analysis. On the other hand, by pooling the data, we can use 2262 (26 years $\times 87$ counties) elements and this is an adequate size.

By employing causality tests (Granger-Sims type), we can infer whether a directional influence by a variable (such as highway expenditures) on another (such as employment) also indicates that the first variable (i.e., highways) "causes" (i.e., consistently precedes) the other. We have employed the only existing, state-of-the-art statistical method that can demonstrate the existence of "causality." Any other reasoning would have to come from outside statistics (e.g., theory, which, until proven, is open to criticism). Causality tests had never before been applied by transportation researchers in this area.

To be sure, we employ causality analysis with caution, fully aware of its limitations. Causality testing is unlikely to indicate two variables are causally related if they actually are irrelevant. However, the strictness of the test can lead to indication of no causality when one would be expected from theoretical or empirical considerations. Knowing this, we have used the consistent behavior of the time-series analysis, when such behavior had a strong theoretical or empirical basis, to indicate causality even in cases in which the causality test was negative. Overall, our analysis is certainly imperfect but where it may have erred this has most likely been on the conservative side.

- By classifying counties in groups following similarities in patterns of characteristics within each group, we can determine the ways in which any relationships we identify may differ across groups. We could further investigate the major causes for the existence and strength of such relationships by making small modifications to these groups. 
- The best remedy to possible misspecification in the timeseries analysis is the inclusion of additional explanatory variables when time-series data on such variables becomes available. Nevertheless, filtering out of the analysis the effects of several exogenous regional and national trends, works to address this issue while also increasing the clarity and significance of our conclusions.

- By employing advanced time-series techniques (such as vector autoregression) we can extend our analysis to all sectors of the economy, concurrently. If desired, we could further investigate the interactions among sectors of the economy as a result of highway investment. 


\section{RESULTS - PART ONE}

\section{IV.1 Total employment}

\section{IV.1.1 Influence of transportation on employment}

Regarding total employment (i.e., the summation of employment for all the sectors of the economy), we have strong evidence that highways "cause" (i.e., temporally precede in a systematic manner) long-term economic development in excess of the normal trend in the regional centers of Minnesota, where twothirds of all Minnesotans work and which absorb approximately half of the Minnesota DOT state trunk highway funds. In each of these counties, \$1 million above the normal expenditures leads to at most 100-140 new jobs, each year, over the next ten years. Of these, a few are created in the second year but most are created in the period between the fifth and the tenth year following the highway expenditures.

There exists no indication of a long-term causal influence of highway expenditures on total employment in the counties that contain the remaining onethird of the workers of Minnesota. For instance, we have no strong evidence that highways influence employment in the counties that are adjacent to the regional centers -- although there exist indications that the effect, if it exists, is likely to be negative, especially outside the Twin Cities Metro Area. We do have some evidence of influence in rural areas (all counties that are not regional centers or adjacent to them) but this evidence is strongest in the short term, i.e. during the period of construction. In addition to construction-related activities, only a small portion of the long term effect 
can occur in this short period; $1 . e .$, there is not sufficient time for new jobs to be created or lost as a result of the higher travel speeds, heavier loads permitted, etc. (Our later research indicates that highway investment has long term impacts on those rural areas that can use the better roads to improve access of farm products to markets, and access of tourists to the area.)

The finding that improved highways tend to favor employment in regional centers and may hurt employment in areas adjacent to such centers should not be surprising. (To be sure, exogenous events such as inflation, unemployment, federal funding, influence employment changes by affecting a group of counties in a similar fashion. In fact, such exogenous events are responsible for the majority of the job growth in a state as recently determined by a Harvard University study. However, as we pointed out earlier, we have employed filtering methods to filter out such effects with respect to the group of counties under analysis.) In particular, we note that regional centers are also economic centers of the state and, therefore, are most likely to have the economic activity that is necessary for absorbing the highway improvements. On the other hand, the areas adjacent to regional centers tend to depend on these centers for the infrastructure necessary for development; better highways allow area residents to conduct more of their economic activities in the nearby centers. (This phenomenon is not as pronounced in the 5 counties bordering Hennepin and Ramsey.) Further, a comparison of the percentage of people working (668) and living (478) in the regional centers strongly suggests that highways are helping the residents of the adjacent counties to get to work as well as provide jobs for them.

The distributional nature of the effects is evident when analyzing the different 
parts of the state. In particular, while certain counties are likely to gain from improved roads, others are likely to lose and the statewide effect is not significant; in addition, the statewide effect is very small in size, i.e., over ten years a 108 investment increase would lead to only a 0.018 increase in jobs statewide (otherwise stated, an extra $\$ 1$ million would create an average of only 5-8 new jobs statewide), most due to the spending associated with the construction of the highway. The negligible economic effect of highway funding on a statewide basis indicates that, except in special cases, the potential for statewide economic gains could not be a valid argument on which to base decisions for increased state trunk highway funding in Minnesota.

\section{IV.1.2 Influence of employment on transportation}

We found that the influence of total employment on highway investment is highly significant statewide, both in the short and in the long term. In addition, the sensitivity of highway investment relative to changes in employment is substantial, i.e. an increase of jobs by a given percentage (say; 10z) above the trend attracts an additional investment statewide of almost double the size in percentage terms -- approximately $18 \%$ over ten years (otherwise stated, an extra 100 jobs attract an extra $\$ 28,500$.$) Following detailed accounting of this$ effect and the stated influence of highways on employment, calculations indicate that, at current funding levels and employment, approximately one of every 60 new jobs in regional centers is created by Minnesota DOT state trunk highway funds.

The influence of employment on highway investment is most significant, both in the short and in the long term (but especially in the short term), in rural 
areas. Thus it appears that the short-term economic well being of the rural counties influences state highway investment policy the most.

\section{2 Sector employment}

Although our analysis concluded that, in general, highway expenditures do not "cause" total employment above the normal trend of economy, highway expenditures may cause the employment within a specific economic sector. (The sectors of the economy examined are, manufacturing, wholesale, retail, service, financeinsurance-real estate, transportation-communications-public utilities, construction, and agriculture.) In particular, we have strong evidence of favorable long-term effects of highway improvements in the wholesale sector of rural counties. Lacking substantial nearby competition, firms in this sector may benefit since their products become more accessible to potential customers, i.e. their sales area increases. Firms may also benefit as transportation cost is an important cost component for their products that are perishable or expensive to transport in comparison to their delivered price.

(We note that our later research also indicates strong evidence of favorable small-scale long-term effects of highway improvements in the service sector of the rural counties that have a strong natural-resource economic base. To be sure, the density of the highway system in these counties of north Minnesota is low with lakes and forests impeding communication in Minnesota and Canada. Better roads have the potential to increase service employment - a sector that represents approximately one-third of the economy in these counties, higher than in most other regions in the state -- by facilitating tourism in the area. Since the total number of jobs in those counties is not very high, even a small- 
scale effect can be important to the local economy.)

However, we also have some evidence of adverse effects on agriculture cash receipts in counties that border the regional centers, and this is in agreement with transportation geography literature. More specifically, the literature has argued to good effect that locations which are close to the fringe of a city may be subject to reduced agricultural activity since farmers expect to sell the land for urban development, and thus are less likely to invest in its upkeep for agricultural purposes. This would be more likely to occur around the Twin Cities metropolitan area, in locations where there are no regulations restricting further development.

Conclusions regarding the relationship between highways and economic development greatly depend on the way in which development is defined. For instance, findings from our ongoing work indicate that, while improved roads may hurt the employment in certain counties, the same road improvements may support increases in household income in those counties. These findings are in agreement with Census data which indicate that 668 of the state's population works in the Regional Center counties while only 478 lives there, implying that about 198 of the state's population commute on highways to their jobs in Regional Center counties from other counties.

Summarizing the above findings, our analysis indicates that:

- The effect of economic development on highway funding is much greater than the effect of highway funding on economic development.

- The effect of the economy on highway expenditures is positive, i.e. the Minnesota DOT reacts to changes in economic conditions by providing more funding to areas in 
which the economy is growing. (However, our later research indicates that, in several rural areas, the effect of the economy on highway expenditures is negative, i.e., the DOT attempts to stimulate their faultering economy by providing more funding; such funding is not as effective in terms of job creation, as the "reactive" type of funding administered in the rest of the counties.)

- For the regions that employ two thirds of Minnesota workers, the Regional Center counties, the effect of highway expenditures on the economy is positive. The effect is also positive in certain rural areas that either have a strong natural resource base (tourism) or can benefit from improved access of their farm products to markets.

A summary of the important long term interactions between highway expenditures and employment is found in Tables 1 and 2. In the Tables, positive and negative signs indicate the sign of the effect from the time-series equations; percentages indicate the level of significance from the causality tests. In interpreting the findings, consistent sign patterns from the time-series equations are important in accepting the results from causality tests.

Table 1. Long-term effects of highway on employment by sector Total Service Retail Wholesale Manufacturing FIRE TCPU Agriculture

\begin{tabular}{|c|c|c|c|c|c|c|c|c|}
\hline State & + & + & + & + & + & + & + & - \\
\hline $\operatorname{Reg}$ Ctr & +18 & +108 & +58 & + & + & + & + & \\
\hline Next RC & - & & & & & & & - \\
\hline Urban & + & + & + & + & + & + & + & \\
\hline Next U & - & - & - & - & - & - & & - \\
\hline Rural & +108 & & & +1 & & & & \\
\hline
\end{tabular}

Table 2. Long-term effects of employment by sector on highway

\begin{tabular}{|c|c|c|c|c|c|c|c|c|}
\hline State & +58 & + & + & + & + & + & + & + \\
\hline Reg Ctr & + & + & - & + & + & + & + & - \\
\hline Next $R C$ & + & + & + & + & & +18 & + & +58 \\
\hline Urban & + & + & + & + & + & + & + & + \\
\hline Next U & & & - & - & & - & + & + \\
\hline Rural & +58 & + & + & - & & & + & \\
\hline
\end{tabular}

FIRE - Finance, Insurance, and Real Estate

TCPU = Transportation, Communications, and Public Utilities

Additional understanding of the role of economic indicators in highway funding decisions can be gained by analyzing the highway program selection process. We have performed such an analysis and have developed a cost/benefit methodology to aid the highway programming decisions -- with an application to spring load restrictions and the forest industry in Northeast Minnesota. 


\section{RESULTS - PART TWO}

\section{V.1 Evaluating criteria for highway project selection}

\section{V.1.1 Introduction}

This analysis addresses the question, "What is the relationship (if any) between highway project funding decisions by the Minnesota DOT and specific indicators, including indicators that the Minnesota DOT uses?" While the analysis was specifically requested by the Minnesota DOT, it is particularly weak because of the relative scarcity of data. Existing data on specific indicators as well as funding decisions are not sufficient for detailed time-series analysis but can only allow cross-sectional analysis, i.e., exactly the type of analysis we strongly criticized in our earlier discussion. Therefore, all results in this section are correlative, 1.e. they simply indicate whether there is a relation between $\mathrm{X}$ and $\mathrm{Y}$ without specifying whether $\mathrm{X}$ precedes $\mathrm{Y}$ or whether $\mathrm{Y}$ precedes $X$. For instance, let us assume that we find a high correlation between the project selection recommendation by the District and the Minnesota DOT funding decision; this could imply that either or both of the following hold, a) Minnesota DOT listens to the District or b) the District "learns" from past Minnesota DOT decisions -- cross-sectional analysis cannot distinguish between the two effects.

\section{V.1.2 1985 project selection - - to fund or not to fund}

We begin by analyzing the data from the 1985 decisions the Minnesota DOT made regarding selection of projects to fund, including Major Construction and 
Reconstruction projects for 1990 and 1991, and Reconditioning and Resurfacing for 1987 and 1988. This analysis determines the major factors that are correlated with the funding decision, i.e. the decision "to fund or not to fund" a candidate project in any of the above 4 categories; the factors include the selection criteria ("point system") now followed by the Minnesota DOT. (For more details on the Minnesota DOT selection criteria see the Appendix.) The major conclusions from this analysis indicate the following:

- The 1985 data indicate that the actual relationship between Minnesota DOT decisions and major criteria it uses to make these decisions is generally close to the relationship stated by the Minnesota DOT. This is particularly true for projects in the Reconstruction category, where the discrepancy is almost nil.

- Of all the point components, Cost Efficiency (CE) and Sufficiency Rating (SR) points are most significant in Major Construction and Reconstruction, while Condition Rating (CR) is most significant in Reconditioning and Resurfacing. Goods Movements (GM) and PM (Peak Month) points are not significant.

- The funding decision is very sensitive to FC (Functional Classification) points in Major Construction and Reconstruction, to $C R$ points in Reconditioning and Resurfacing, and to SR in Major Construction and Reconstruction. Any reporting inaccuracies would be highly magnified, 2 to 5 times in these cases. As an example, a discrepancy of half a point in CR can shift the probability of funding for a typical Resurfacing project by 35 points on a 0-100 probability scale. Therefore, extreme care is needed, especially when recording $C R$ and $S R$, where a measurement error can easily arise.

- The priority each District assigns to the projects it submits for consideration is the most consistently significant factor in the funding decision. The contribution of this factor to the decision often equals that of all other factors combined. Further, the funding decision is sensitive to the District priority; if the District raises its priority rating by a point (scale 1$10)$, the probability of funding is raised by approximately 10 points (scale $0-100$ ).

ADT is a significant factor in Reconditioning and Resurfacing but is almost irrelevant for Major Construction decisions. However, ADT-related factors, e.g. Commercial 
ADT (in Major Construction) and ADT divided by cost/mile (in all cases) are often more significant than ADT. The sensitivity of funding to ADT is highest in Reconditioning and lowest in Major Construction. For instance, on a 0-100 point probability scale, a 1000-car ADT increase can raise the funding probability $2-6$ points in Reconditioning, and 1-2 points in Reconstruction and Resurfacing; however, in Major Construction a 10,000 car increase would hardly make a difference in funding.

\section{V.1.3 1972-1985 project funding .. how much to fund}

The 1985 data set was unique in that it contained both the projects that were funded and those that were not. As a result, it was possible to determine the significance and the weight of the factors that may have helped shape the outcome of the "fund/no fund" decision. Unfortunately, the Minnesota DOT data for prior years refer only to the projects that were funded. As a result, we can only use those data to determine the significance of factors that may influence the amount of funding. More precisely, the question we seek to answer must be modified to, "Given that a project is selected for funding, what is the relationship (if any) between the amount of funding and specific indicators, including indicators that the Minnesota DOT uses?" Because of data limitations, this analysis considers all 4 project categories together.

Remarkably, the relationship between $A D T$ and funding per mile has remained stable since 1972. As expected, this relationship is positive, i.e. higher ADT corresponds to higher funding per mile. In particular, for every 10-percent ADT increment on a highway to be funded, we can expect a 6-8 percent corresponding increment in funds per mile for that project on the average, after adjusting for inflation. 
The relationship between $C R$ (all CR data are from 1980) and funding is negative as expected, i.e. higher $C R$ corresponds to lower funding per mile. In particular, for every 10-percent increment in CR, we can expect a 30-60 percent corresponding decrease in funds per mile for a typical project. Because of the extremely high sensitivity of funding to $C R$, a half-point error in measuring $C R$ could result in a funding difference of up to $\$ 450,000$ for a typical 5-mile project.

The data indicate a positive relationship between funding and either income or employment. This implies that more highway funds become available to areas of higher income and/or employment. This was generally expected for two reasons. First, a positive relationship has already been found between funding/mile and both ADT and commercial ADT, economic indicators that are substantially correlated with income ( correlation between ADT and income $=52-668$ ) and are already included in the project selection process. The second reason is that, in most counties, a positive relationship has been found in our time-series analysis presented earlier -- indicating a "reactive" mode of DOT policies to changes in the economy. To be sure, the results from that analysis are far more detailed and reliable (they were able to also identify cases in which the DOT policy is stimulative, not reactive) than the exaggerated numbers our correlative analysis produces; therefore, we shall not cite any of the latter.

Nevertheless we can use the results from the time series analysis to interpret the findings of the cross-sectional analysis. In particular, since the timeseries results indicate that, statewide, the interaction between highways and the economy is significant only in the direction of economy influencing highways, we interpret the cross-sectional results as supporting the view that 
economic indicators such as the District priority rating, ADT, employment, and income (in that order) influence highway investment decisions in a significant and substantial manner, $1 . e .$, in most cases, better economic conditions attract, with a lag, increased highway funding.

\section{V.2 Highway project selection and simulation of project impacts}

\section{V.2.1 Highway project selection based on long term benefit-cost analysis}

In this section we are concerned with the ways expected benefits and costs (including any possible direct and indirect economic impacts) of highway projects can be considered for highway project selection. In particular, we develop an algorithm for obtaining a road development program that optimizes the relationship of costs and benefits of the projects in that program while meeting a specified budget constraint. Although we concentrate our analysis in selecting projects that deal with changing the weight carrying limits on the state highways, our methodology is formulated in a general manner so that it could be applied to other types of projects and, therefore, could be used to aid the highway project selection process of the Minnesota DOT.

Because a regional highway network serves a considerable number of plants and markets and consists of a large number of links, the benefits resulting from improving a single link of the network are almost never immediately realized. Alternatively, the network links could be upgraded in sets so that the lowest construction costs result in the maximum realizable benefits. In the case of weight limits, a benefit is realized only when the minimum load limit along a travel route is raised, and it is this special feature (constraint) that makes 
the problem interesting.

We apply our analysis to transportation benefit and cost data from the forest industries and the highway system in northeast Minnesota. In this application, changes in weight restrictions, in the direction of upgrading and expanding year-round 10 -ton state routes, are expected to affect the transport cost per mile and the direct yearly net benefits. For instance, assuming constant demand and supply between origins and destinations, the direct benefits depend on the number of saved trips, the transportation unit cost, the length of trips and the time period in which the benefits occur. If the shipping patterns of forest industry products remain consistent with previous shipping patterns and the number of shipments is not reduced by the closing of forest plants, then the Impact of upgrading a forest product route may be significant.

The realized economic net benefits of road investments are quantified through the transportation cost reductions. However, the net benefits vary among the industries of an economic sector because the method of transportation cost payments varies from one industry to another. In the forest industry, for instance, an examination of alternative payment structures is necessary because changes in factors affecting the transportation cost determine different schemes of benefits for the shippers and the freight carrying companies. Some shippers pay the freight carriers a flat rate for the movement of their products. Others, contracting with independent truckers, pay by the loaded miles, by the running mile, or by the loaded miles with an additional hourly rate for time spent at the truck terminal. Shippers who lease trucks pay according to a lease agreement. In the first payment alternative, transportation cost reductions are a benefit to the carriers, while in the rest of cases the benefits are enjoyed 
to a larger extent by the shippers. We have analyzed all major alternative payment structures and have used the raw data to draw conclusions that apply to all industries included in this work.

The algorithm developed here solves the problem of combining the maximum realizable economic benefits, resulting from the alleviation of weight restrictions or other road improvements, with the minimal incurred construction costs, expended for the upgrading of the network links. Both benefits and costs are amortized over the time horizon appropriate for each project. The objective is maximization of the total net benefit summed over all customers and all commodities subject to the total available budget over the planning horizon. The algorithm considers two maintenance policy alternatives regarding the route capacity of the network:

(a) Road $(i, j)$ from origin $i$ to destination $j$ is upgraded to carry heavier loads. Alternatively,

(b) Road $(i, j)$ is not upgraded but is still used for heavier loads. This would lead to a reduced expected 1 ife and an increase in the maintenance costs.

The set $U$ of all feasible project combinations includes upgrading combinations that lead to the same final outcome but are accomplished in a different sequence. For instance, a 9-ton road may be upgraded to 10-ton directly; alternatively (and this would be considered a different project in $U$ ), the 9 -ton road may be partially improved at first, e.g., to 10 -ton for 10 months. To be sure, the cost of upgrading a highway in steps is higher than making the complete improvement at once.

The nature of the relationship between the total optimal benefit $Z$ and the available budget $W$ is illustrated in Figure 1 . In general, the set $U$ initially 


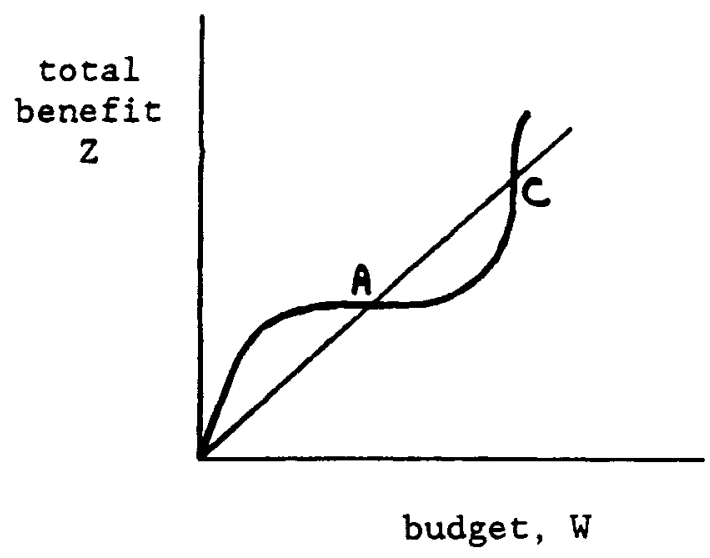

Fig. 1a Beginning with $B / C>1$

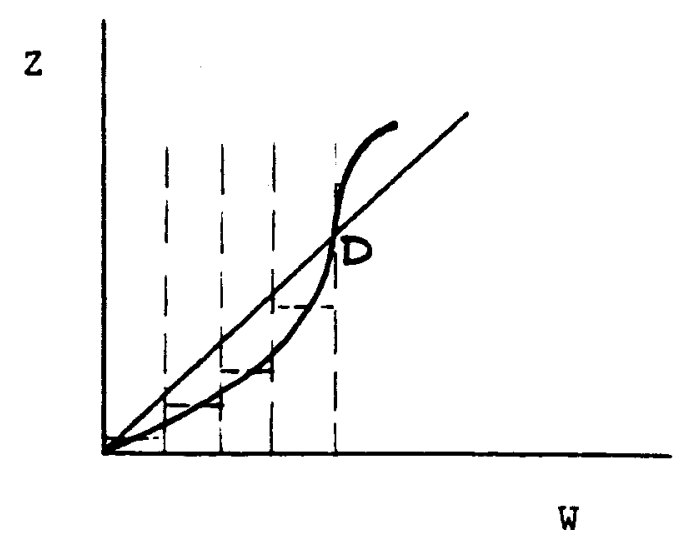

Fig. 1b Beginning with $B / C<1$

Figure 1. Total optimal benefit as a function of available budget

may contain one or more small projects, the completion (upgrading) of which leads to immediate completion (upgrading) of one or more complete routes. If such projects are present in $U$, the curve of Fig. la begins with a B/C ratio greater than one. If, on the other hand, no such project exists in $U$ initially, the rate of accumulation of the total benefit $z$ is slow and the curve begins below the breakeven $(B / C-1)$ line as $\mathrm{Fig}$. Ib indicates. As more road segments are completed, the benefit accumulation rate accelerates and the curve of Fig. Ib may again cross the breakeven line as it enters a range where $B / C>1$ at some stage (point D). Towards the end, when most important routes in the network have been upgraded, the rate of increase of $\mathrm{z}$ slows down again.

\section{V.2.2 Case study in Northeast Minnesota}

The objective of the case study is to analyze the economic viability of upgrading the spring weight restrictions on the state highways of northeast Minnesota. In particular, the case study focuses on evaluating the network upgrading on the basis of realized net benefits from the paper and waferboard 
product industries of that region. Direct benefits would accrue if the network upgrading reduced transportation costs and, thus, made the final production cost of the above forest products more competitive in the nation's markets. These industries could, then, increase the production capacity of their plants and, in time, their export market share in the national and international markets.

While transportation cost is an important factor in the final cost of the voluminous forest products, organized cost and shipment data do not exist or are incomplete - therefore, we had to collect the necessary data and thus create a complete database for our analysis. In particular, the difficulties associated with the collection of reliable data and data confidentiality are often cited as the two major reasons for the lack of complete data. In order to obtain a more complete database on paper and waferboard product shipments, we conducted a survey in northeast Minnesota in 1985. The survey sought information on shipment origins and destinations, cost structure, tonnage, modal split, shipment value, trip duration, etc. for the nine leading woodpulp mills in the area. The paper and waferboard producers belonged to the following companies: Potlatch, Blandin, Northwood Panelboard, Boise Cascade, Superwood, Conwed, Diamond International, and Great Lakes Forest Products. A summary of relevant data from these producers is presented in Tables 3 and 4.

In addition to the information summarized in Tables 3 and 4 , the responses to our survey indicated that the transportation cost is an important component of the final price of paper and waferboard, especially for shipments outside Minnesota. No surveyed company disclosed product demand data at the customer, town or city level. As a result all our demand data are at the state level. We expanded the above database with data related to the principal highways the 
Table 3. Active pulpwood mills and waferboard plants in northeast Minnesota by location and capacity as of 1982

$\begin{array}{lll}\text { Company } & \text { Location } & \text { Capacity } \\ \text { Woodpulp Mills } & & \text { (tons/24 hrs) } \\ \text { Producer X } & \text { Grand Rapids } & 300 \\ \text { Producer Y } & \text { International Falls } & 920 \\ \text { Producer Z } & \text { Cloquet } & 475 \\ \text { Producer T } & \text { Bemidji } & 100 \\ \text { Producer U } & \text { Duluth } & 350 \\ \text { Producer V } & \text { Cloquet } & 50 \\ \text { Waferboard Plants } & & \\ & & \text { (est tons/yr) } \\ \text { Producer A } & \text { Grand Rapids } & 270000 \\ \text { Producer B } & \text { Bemidji } & 160000 \\ \text { Producer C } & \text { Bemidji } & 150000 \\ \text { Producer D } & \text { Cook } & 150000\end{array}$

Table 4. Data Summary of Forest Product Producers in NE Minnesota*

\begin{tabular}{cccccccc}
\hline & $\begin{array}{c}\text { max distance } \\
\text { between plant } \\
\text { and market } \\
\text { (miles) }\end{array}$ & $\begin{array}{c}\text { max distance } \\
\text { between plant } \\
\text { and market } \\
\text { by truck } \\
\text { (miles) }\end{array}$ & $\begin{array}{c}\text { transp cost } \\
\text { (m/mi) } \\
\text { truck }\end{array}$ & $\begin{array}{c}\text { rail } \\
\text { flat-bed } \\
\text { truck }\end{array}$ & $\begin{array}{c}\text { Shrogular } \\
\text { common } \\
\text { carriers }\end{array}$ & rail \\
\hline 1 & 1800 & $\mathrm{U}$ & 1.2 & 2.5 & 23 & 23 & na \\
2 & 2100 & $\mathrm{U}$ & $1.1-1.4$ & $2.2-5.5$ & na & na & 51 \\
3 & 48 states & 800 & 1.2 & 3.5 & 23 & na & 75 \\
4 & 48 states & 800 & 1.2 & 3.5 & 23 & na & 75 \\
5 & 48 states & $\mathrm{U}$ & $1.1-1.3$ & na & na & 23 & na \\
6 & 48 states & $\mathrm{U}$ & $1.1-1.2$ & na & 23 & 18 & na \\
7 & 700 & 700 & NA & 1.0 & na & 22 & 62 \\
\hline
\end{tabular}

* - for confidentiality purposes, not all producers are listed.

$U$ - unlimited; depends on market conditions and order size.

na - not applicable; mode not used.

NA - not available 
forest industries use in northeast Minnesota. We used these data, provided by the Minnesota Department of Transportation, to develop the layout of the relevant highway network, illustrated in Figure 2. The Minnesota DOT classifies these highways in three load categories, i.e.,

a) E - category: 9-ton roads operated as 10-ton in the 3 winter months,

b) F - category: 9-ton roads operated as 10-ton for 10 months, and

c) G - category: 10-ton roads year-round.

Using the above information, the principal highways of NE Minnesota were segmented into links by load category and estimated remaining life -- see Table 5. Our algorithm was then used to analyze these highways with the help of a personal computer. The computer code accepts the road length and remaining life of highways, and the number of truckloads between origins and destinations as inputs. The output is a prioritization of the available projects subject to a budget constraint. The project prioritization results are based on the assumption that the realizable project benefit per truck load is approximately 3 short tons, i.e., the difference between the currently allowed 73820 pounds GVW and the desirable 80000 pounds GVW. No effects were considered that relate to possible truck detouring or plant closing because of road deterioration.

Based on the algorithm, only the segment of Trunk Highway 33 ( $\mathrm{TH} 33$ ), connecting Interstate 35 (I-35) with Cloquet (see Figure 3) has a benefit/cost ratio greater than 1. From all candidate upgrading projects considered, the following were selected in order of priority (the selection is based on $B / C$ ratios that are calculated from the data received from the industry and the Minnesota DOT; these data, as is the case with all data, are subject to errors): 


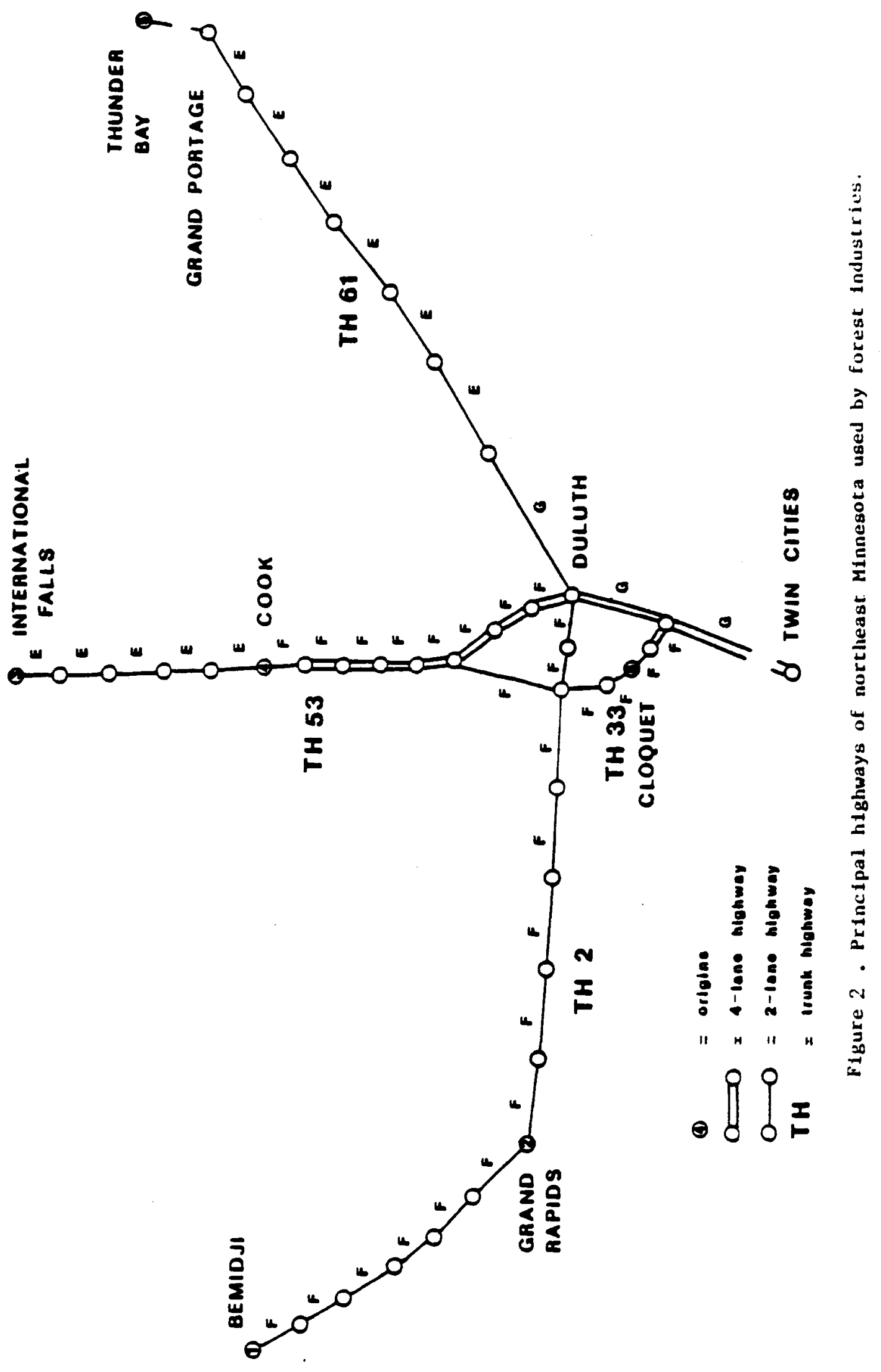


1. TH 33, from I-35 to Cloquet; upgrade to 10-ton road year round.

2. TH 33, from Cloquet to TH 2; and

$\mathrm{TH} 2$, from $\mathrm{TH} 33$ to Grand Rapids; to 10 -ton year round.

3. TH 53, from Cook to International Falls; to 10-ton for 10 months.

4. TH 2, from Grand Rapids to Bemidji; to 10-ton year round.

5. TH 61, from Two Harbors to U.S. border; to 10-ton for 10 months or year round.

6. TH 33, from $\mathrm{TH} 2$ to $\mathrm{TH} 53$, and

$\mathrm{TH}$ 53, from $\mathrm{TH} 33$ to International Falls; to 10-ton year round.

All prioritized projects are placed on the Minnesota map of Figure 3 . The cumulative B/C ratio of the projects (see Figure 4) illustrates the lack of attractiveness of all projects once the first one is selected. To be sure, the low cumulative $B / C$ is mainly the result of considering the direct benefits accruing to only one customer, i.e., the forest industry. Nevertheless, the forest industry is a major user of the NE Minnesota highways and this implies a high likelihood that the above projects would not be attractive, even if additional users were considered. [The Minnesota DOT has recently alleviated weight restrictions on TH 2 based on highway engineering criteria (deflection tests) and is considering upgrading TH 33 from I-35 to Cloquet.]

The above analysis does not consider the indirect cost of not tending to deteriorating highways in a timely fashion. For instance, roads of low quality may cause truck detours and higher transportation cost. When the cost crosses a certain threshold, that the industry considers unacceptable, that industry may relocate; similarly, new industry may not be attracted. Further, the analysis does not consider any rerouting that may take place following partial upgrading of the network. However, the centralized nature of the NE Minnesota network substantially reduces the possibility for such rerouting. 
Isble 5. Tronk bichers of sorthesst Ki ane soca osed by forest iadustrios

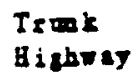

4
25
24
8

T. 53

Gered

Rnpids

$\begin{array}{rr}9.9 & 18 \\ 0.35 & 9 \\ 12.35 & 38 \\ 6.95 & 14 \\ 27.35 & 29 \\ 21.8 & 24\end{array}$

Bnidut

53

Dolnes

7.0
8.64

2.91

6
10
21

$$
\begin{aligned}
& 7.25 \\
& 9.94
\end{aligned}
$$$$
1.36
$$

$\begin{array}{rr}6 & F \\ 10 & F \\ 21 & F\end{array}$

T: 33

$\begin{array}{rrr}1.67 & 21 & 12.03 \\ 16.97 & 7 & 8.54 \\ 16.03 & 4 & 16.09 \\ 11.85 & 18 & 9.86\end{array}$

$\begin{array}{rr}21 & 5 \\ 7 & 8 \\ 4 & 8 \\ 18 & 8\end{array}$

Cook

22.21

19

38

2.00

29.76

17.26

18.07

3.25

Internationsl

Balls

61

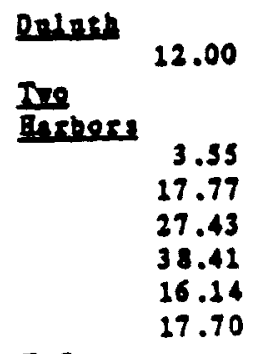

D.s.

Borter 


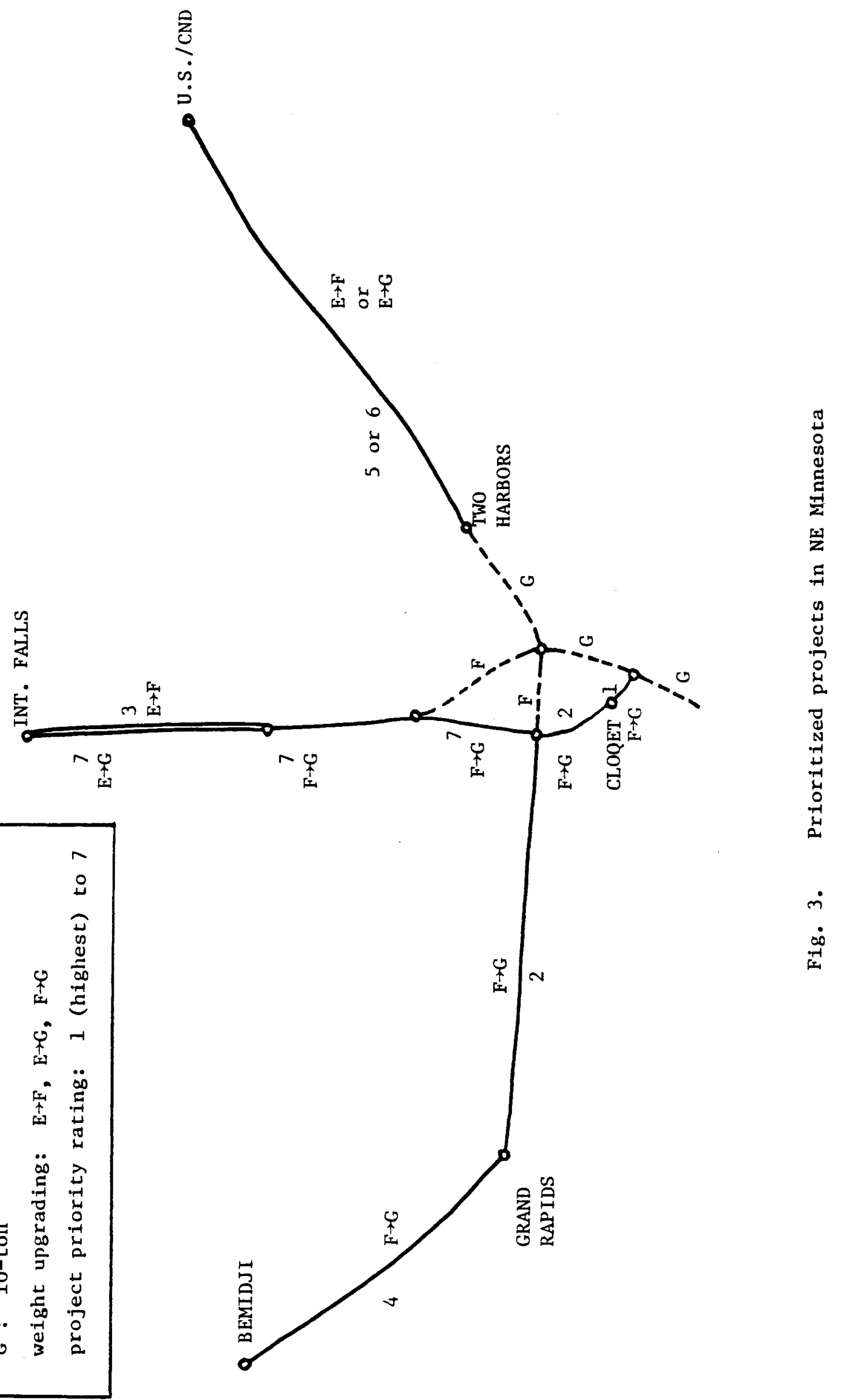




\begin{tabular}{|l|l|}
\hline \multicolumn{2}{|c|}{ Selected } \\
\hline Rank & Projects \\
\hline 1 & 1.3 \\
2 & 0.23 \\
3 & 0.13 \\
4 & 0.09 \\
5 & 0.03 \\
6 & 0.03 \\
7 & 0.03 \\
\hline
\end{tabular}

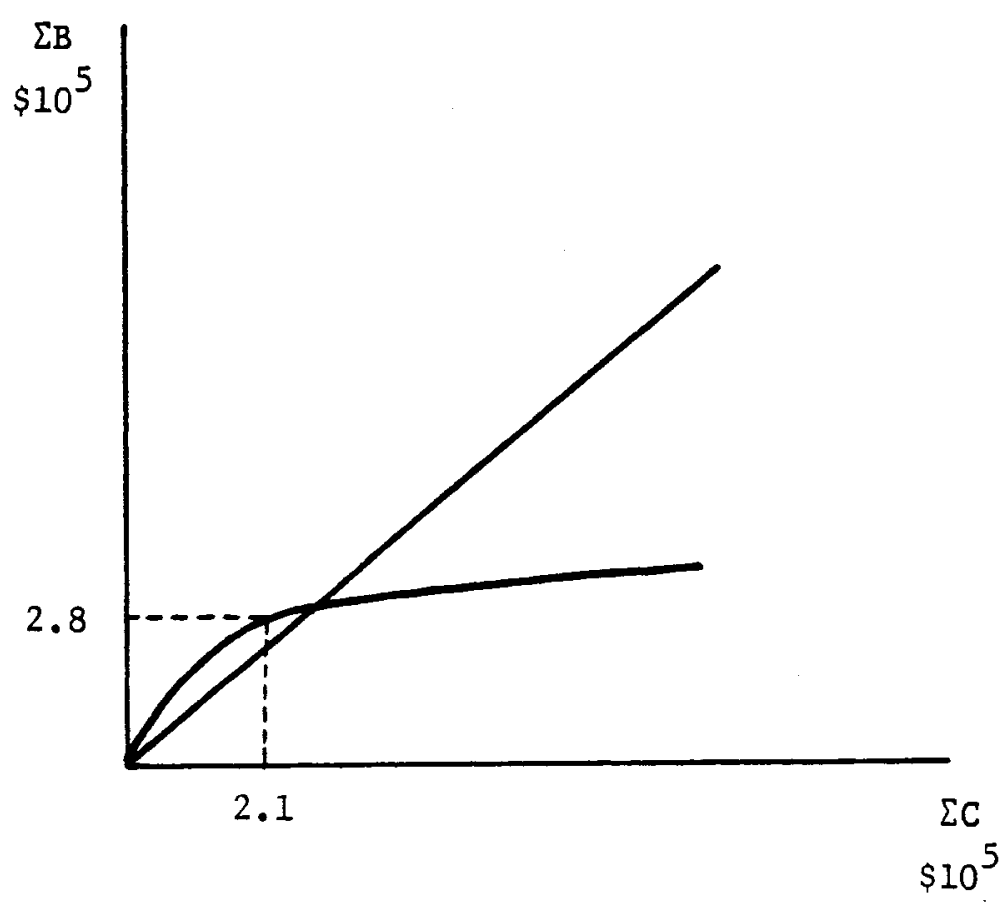

Fig. 4. Cumulative $B / C$ for the selected projects in NE Minnesota 
As part of the case study, we have also used an alternative indirect analytical method to assess the economic effects of a transportation policy in Northeast Minnesota. In particular, we assess the possible economic effects on the local forest industry of increasing all spring load restrictions in NE Minnesota to 10 tons year round. To accomplish this, we use the large-scale Input-Output SIMLAB economic simulation model appropriately modified to handle this regional problem. While SIMLAB does not determine whether the spring load restriction is economically efficient, it does determine all the effects - - both primary (direct) and multiplier (indirect) of the restrictions. The benefit-cost analysis described above can then be performed based on this information.

The timber industry sectors considered include logging, sawmills, particle board, other wood products, pulp and paper. For our base-case analysis we use the status quo in 1977. At that time, some roads were restricted to 7 tons for part of the year and most allowed 10-ton loads except in spring when they were restricted to 9 tons. From our interviews with the major local companies, it is evident that the increase in weight carrying capacity will enable most companies to increase their truckload shipments while maintaining the same transport cost, since they now must ship a given number of truckloads at a higher cost. In this analysis, we assume that all the cost savings are passed onto the purchaser.

For the regional economy as a whole, a 18 decrease in transportation cost can lead to only a small increase in gross output and earnings that should not be expected to exceed 0.02\%. (However, individual sectors can do better and can reach as high as 0.17 for the particle board sector.) The total increase in regional output with upgraded weight limits is estimated as a function of industry market share. For instance, if we assume that the lower transportation 
cost results in a relatively small increase of the market share of the industry, then regional output is expected to increase by $\$ 70,000$; similarly, if we assumed a market share increase ten times as large, the corresponding output increase would be $\$ 700,000$. (To be sure, the benefits would probably increase if all small forest companies were also included in the analysis.) Tax revenues from this increase could support upgrading a total highway length of between 5 and 50 miles based on current tax and cost estimates, where the low end of the scale supports the earlier benefit/cost analysis conclusions that pointed to the need for upgrading the 5-mile stretch of road from I-35 to cloquet.

One of the prime findings of this avenue of investigation was that application of this method to other industries and other areas in Minnesota is feasible. (This finding does not apply to the use of the Input-Output simulation model, which is not operational for all regions of Minnesota.) An additional factor that should be considered when applying this method to other industries and other areas in Minnesota is the time value of the products being shipped. While timber products have some inventory value if not shipped during the weightrestricted season, products such as grain, not only have inventory value but can also have significant price fluctuations. If grain is to be shipped during the weight-limited season, the entire annual harvest may have to be shipped inefficiently. Upgrading the roadway would, then, have much more substantial results than in the case of the timber-related industry of Northeast Minnesota. 


\section{RECOMMENDATIONS}

1. The 7 counties that employ two-thirds of Minnesotans and constitute the regional economic centers of the state (Hennepin, Ramsey, st. Louis, 0lmstead, Stearns, Blue Earth, and Clay) can demonstrate significant and sizeable long-term employment improvements following increase of transportation investment (as evidenced by the Granger-Sims causality test, the structural plots, the vector autoregressions and the elasticities). This finding is particularly relevant for the state economy in view of the fact that the Regional Center counties earn 718 of the state income, contain approximately half the state population, and absorb nearly half the Minnesota DOT trunk highway funds (source: Minnesota DOT data.) In addition, natural-resource base counties in ruxal north Minnesota can use better transportation to improve their service economy. If government policy is to promote jobs in these counties, better transportation can help.

2. The counties that border the 7 economic centers may demonstrate a worsening job climate, especially in agriculture, with improved roads, especially in the 5 centers away from the Twin Cities (as evidenced by the vector autoregressions, the structural plots and the elasticities). However, highways that improve commuting may alleviate some of the hardships of an economic slowdown. If highway improvements enable workers to commute more easily to the nearby centers of economic vitality, income in the border areas may increase (as evidenced by our ongoing work) although employment will be transferred to the centers. Nevertheless, the transfer of employment from the adjacent counties to 
the centers is likely to attract new businesses to those centers and away from the adjacent counties in the long term (as suggested in the literature and by our previous work for the U.S.DOT). If government policy is to improve the economy in the areas adjacent to the economic centers, government should clarify which aspect of the economy it wishes to improve using transportation investment: income may improve but jobs may suffer, To be sure, it could be correctly argued that creation of jobs is significant even if they are not in the same county as that in which the worker lives. For instance, it would seem possible that some of the jobs created in the regional center counties may be jobs that otherwise would have been lost to the entire area (i.e., regional center plus adjacent counties) if the jobs in the regional centers had not been there. However, since no additional jobs are created statewide, this argument would lead to the conclusion that most of the "lost" jobs would have been gained by the rural areas of the state, not by other states.

3. An economic center can use better highways to stimulate its employment; however, some of this employment improvement may occur at the expense of its neighboring counties (as evidenced by the vector autoregressions, structural plots and elasticities). If government policy is to improve employment in all of Minnesota. this cannot be accomplished using the transportation investment tool alone (note, however, that our method could also be employed to estimate the expected effects of other types of state expenditures on economic development); any effects improved transportation may have are relative rather than absolute, e.g. regional center policy makers should be 
aware of the negative impacts the improved highways may have on their neighbors, of course, the relative or distributional nature of certain impacts may well be socially and politically desirable. For instance, even though increased highway funding in rural areas may have a small benefit/cost ratio in terms of direct dollar benefits and costs, the funding may provide sufficient support to stabilize a declining town and this social effect may be hard to include in a conventional benefit/cost analysis. Even in such a case, however, care should be taken that the increased highway funding does not result in draining the local economy while the closest large urban area gains (as would happen, for instance, if the improved transportation attracted new industries and services to the urban area; made industries and services of the smaller town to relocate to the urban area; made products and services of the small town to lose in competition to lower-priced products and services of the urban area; made consolidations of services, e.g., banking, educational, religious services, in favor of the urban area necessary.)

4. Strong evidence of favorable long-term employment effects of highway improvements in rural areas (i.e., areas not in the Regional Center or Next-to-Regional-Center counties) was found only for the wholesale sector. However, this long-term effect does not last long, probably not more than 8 years following the highway expenditures (as evidenced by the causality test, the vector autoregression and the structural plot). Strong evidence of favorable long-term effects was also found in rural areas that either have a strong natural resource base, e.g., tourism, or can benefit from improved access of their farm products to 
markets; although such effects would involve few jobs, they could still be important to the local economy. Favorable effects in other sectors of the rural areas were found only in the short term, i.e. during construction, and most would be construction-related. Therefore, if government policy is to stimulate employment in rural areas, it can accomplish this during the construction of highways. If policy is to achieve long-term improvements, government can improve transportation to achieve this in some sectors: however. in most sectors, transportation improvements alone would not be sufficient and would have to be accompanied by additional development policies,

5. Highway funding alone cannot stimulate Minnesota agriculture (as evidenced by the causality tests, the vector autoregressions and the structural plots, and as already discussed in $\# 4$ above).

6. The current Minnesota DOT project selection process is very highly responsive to the recommendations of the individual districts. The data and the significance tests indicate that district recommendation (reflecting, among other factors, current economic conditions) contributes to the process as much as all other selection factors combined. Therefore, there is no need to use additional economic criteria as long as the Minnesota DOT plans to continue to place such a substantial weight on the district recommendation. To be sure, there exist certain limitations in generalizing this conclusion as it has been drawn from the only available data, i.e. the data on the 1985 decisions on major construction and reconstruction projects for 1990 and 1991, and reconditioning and resurfacing for 1987 and 1988 . 
Nevertheless, we have indications that 1985 was a fairly typical year in the project selection process.

7. Our time-series analysis indicates that the Minnesota DOT is highly responsive to the economic (employment) conditions of Minnesota in two ways: First, in most cases the DOT plays a strongly passive, reactive role in state and regional economic development by increasing highway investment where the economy is Improving -. a role that is largely effective. Second, in certain rural counties the DOT plays a stimulative role by providing more funding when their economy is faultering - a role that is, for the most part, ineffective. In particular, although the evidence indicates that increased highway investment is most effective in favorably influencing the economy of the regional centers of the state and of certain natural-resource and farm-product based rural counties, it is the economic (employment) conditions of all rural areas that exert the most significant influence on Minnesota DOT highway funding decisions. It can be inferred that, unless the state's development priorities are to be changed, inclusion of additional economic criteria in the Minnesota DOT highway project selection process is not needed.

8. If the state's priorities are that the economies of the regional centers should not be improved at the expense of the outlying economies, the evidence indicates no need to use additional economic indicators as criteria in highway programming. The political climate in Minnesota, with a thriving economy in the economic centers and a depressed economy in many areas of Greater Minnesota, is to encourage 
economic development outside the centers. Our analysis indicates that any attempt to further improve the employment of the centers by Improving transportation may also have adverse employment effects on their neighbors. To be sure, such adverse effects would be tempered by the income increase of the residents in the areas adjacent to the economic centers who can use the improved roads to commute to the centers -- these commuters represent 198 of the state's population (as pointed out elsewhere, this observation is also supported by results from our ongoing work).

9. While including economic indicators in highway programming to stimulate the economy is not justified, the use of additional economic indicators such as employment and income may significantly improve the Minnesota DOT forecasts of future ADT levels as our regression analysis and correlation results indicate. (Our previous reports indicate -- see Appendix for details -. that ADT is highly correlated with both employment and income.) Our review of Minnesota DOT's programming selection procedures revealed the importance of accurate ADT forecasts for reconditioning and resurfacing projects. However, these forecasts are usually only extrapolations of past trends. The forecasts can be improved by using time-series techniques such as the ones used here.

10. Minnesota DOT should optimize the uniformity and consistency in measuring condition and sufficiency ratings. Highway project selection and funding decisions are extremely sensitive to $\mathrm{CR}$ and $\mathrm{SR}$ measurements (as evidenced by our regression analysis and significance tests); small recording errors may have a substantial effect in project ratings. 


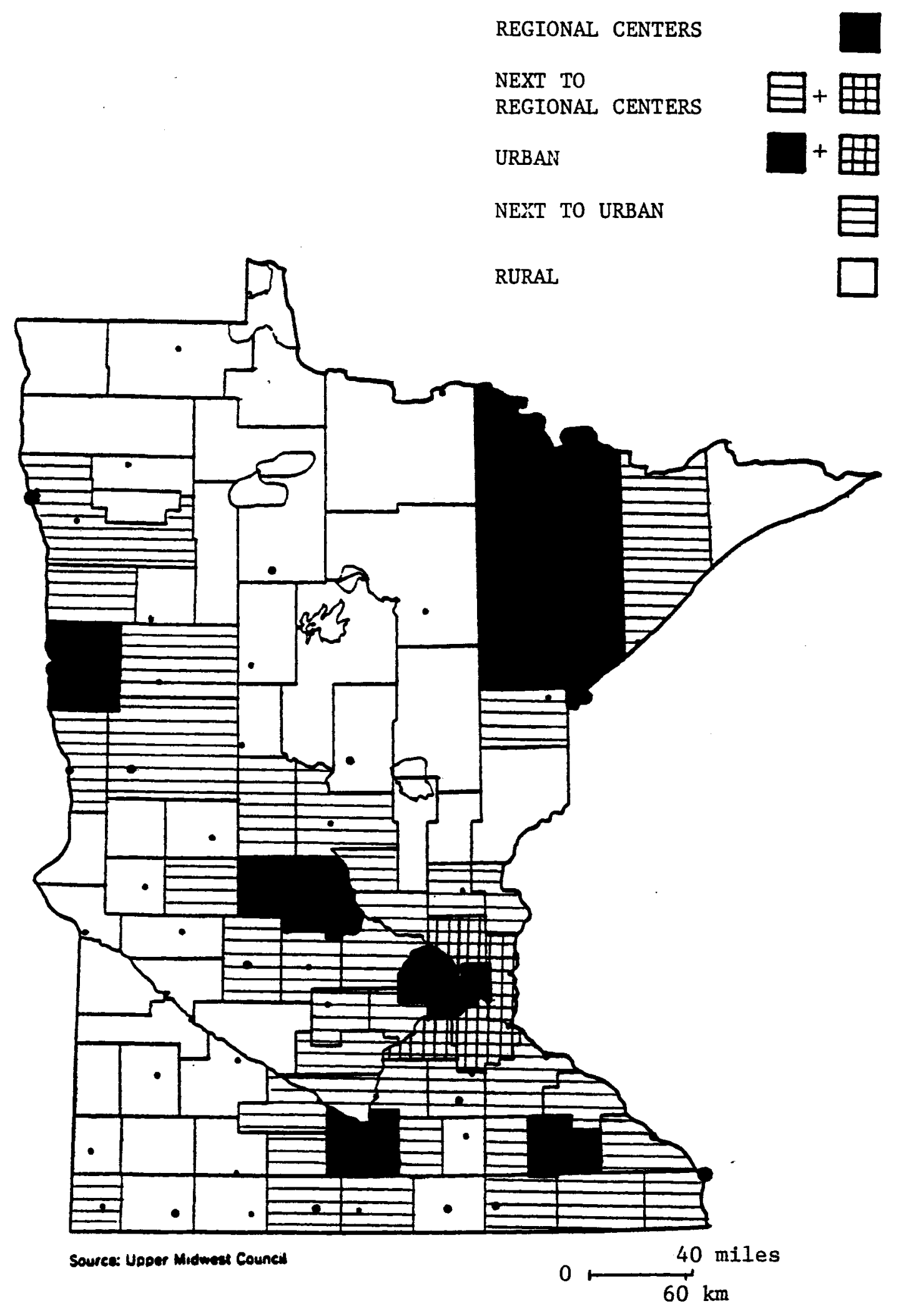

FIGURE 5. County Groupings 


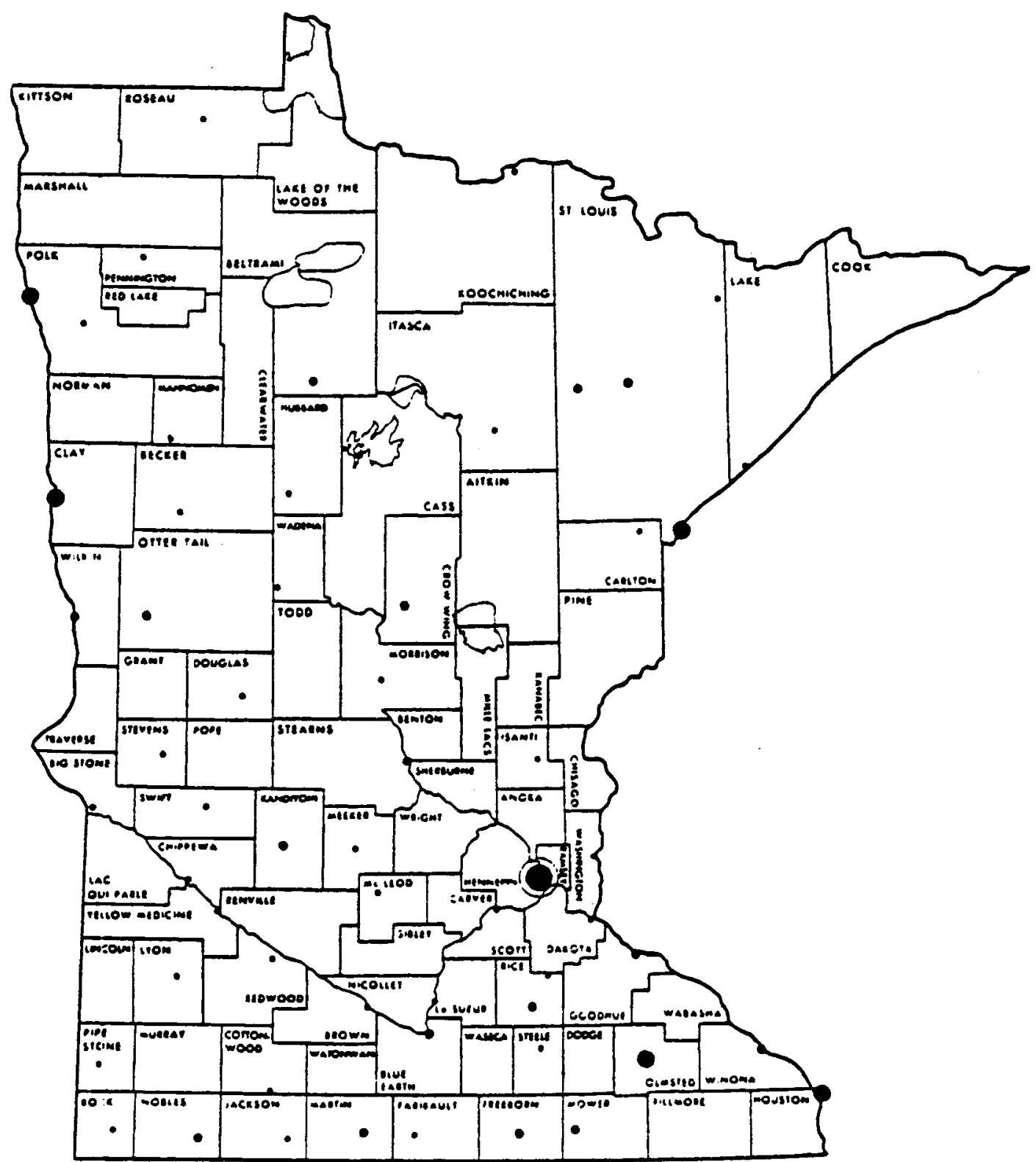

Source: Upper Midwest Council 


\section{TRANSPORTATION AND ECONOMIC DEVELOPMENT}

Final Report : Executive Summary

Yorgos J. Stephanedes

Department of Civil and Mineral Engineering University of Minnesota

Minneapolis, Minnesota 55455

May 1989 
States have recently assumed a greater role in facilitating economic development. A major part of state programs has been shaped by public investment policies directed to easing transportation-related physical barriers to development. For instance, Departments of Transportation in 36 states explicitly consider regional economic development in highway program selection. The consideration of the economic development criterion rests on the premise that there exists a relationship between transportation investment and the economy. Empirical analysis, however, has led to little agreement in the literature as to the nature of such a relationship. Researchers agree that the more mature, complex and well-connected the transportation system is, the harder it is to predict whether transportation improvements will help the local economy. This result is of particular interest to Minnesota, a state with a transportation system that is both well developed and well connected.

This report summarizes the results of a project undertaken by a University of Minnesota team for the Minnesota Department of Transportation to determine the existence and extent of relationships between transportation and economic development in Minnesota. The interdisciplinary team was directed by the Department of Civil \& Mineral Engineering and included experts from Civil \& Mineral Engineering, Geography, Economics (Twin Cities and Duluth campuses), Applied \& Agricultural Economics, Industrial Engineering \& Operations Research, and Regional Economics.

\section{BACKGROUND}

Regional economic development impacts of highways have been empirically evaluated in Japan, the Soviet Union and the U.S. The majority of the evaluation studies have used cross-sectional, correlational analysis, which is unable to determine the direction of causality between two variables. For example, a correlation between highways and development may be due to highways following development or highways causing development. By contrast, this project employs time-series analysis, which can come substantially closer to distinguishing between cause and effect as well as estimate the extent of any impact through time.

The traditional view in the literature has been that the improvement of transportation infrastructure is a necessary predecessor to economic development in a region. However, in the last 10 to 15 years studies pointed out that transportation can be a concurrent or resultant of rather than a predecessor to regional economic development. Similarly, the development of transportation was found to exacerbate rather than reduce economic development differentials between the major cities and rural regions in certain countries. In addition, the direction of long run impacts can be different from that of short run impacts. Further, in certain economic sectors, if a state has a good highway net, highway investment is more likely to reallocate employment between different parts of the state than to generate new employment. Previous work has operated at substantially different geographical scales, ranging from largescale multi-state regional studies to small urban land use projects, and based on a wide range of implicit assumptions, thus leading to inconclusive and occasionally contradictory findings.

In summary, the complexities of the interdependencies between places in a well integrated spatial economic system, such as in Minnesota, imply that the effects 

By classifying counties in groups following similarities in patterns of characteristics, we filter out the effects of exogenous variables and can determine the ways in which any relationships we identify may differ across groups.

- Filtering out the effects of exogenous regional and national trends works to address the need for additional explanatory variables, while also increasing the clarity and significance of our conclusions.

- By employing advanced time-series techniques (such as vector autoregression) we can extend our analysis to all sectors of the economy, concurrently. If desired, we could further investigate the interactions among sectors of the economy as a result of highway investment.

\section{TIME SERIES FINDINGS}

\section{Interactions between transportation and total employment}

Regarding total employment (i.e., the summation of employment, by place of work, for all sectors of the economy), we have strong evidence that highways "cause" long-term economic development in excess of the normal trend in the regional centers of Minnesota, where $2 / 3$ of all Minnesotans work and which absorb approximately half of the Minnesota DOT state trunk highway funds. In each of these counties, $\$ 1$ million above the normal expenditures leads to 100-140 new jobs, each year, over the next ten years. Of these, a few are created in the second year but most are created in the period between the fifth and the tenth year following the highway expenditures.

There is no indication of long-term causal influence in the counties that contain the remaining one-third of Minnesota workers. For instance, we have no strong evidence that highways influence employment in the counties adjacent to regional centers - although there exist indications that the employment effect, if it exists, is likely to be negative. However, our analysis also suggests that highways are helping the residents of the adjacent counties to get to work, and provide jobs and income for them. We do have some evidence of influence in rural areas (all counties that are not regional centers or adjacent to them) but this evidence is strongest in the short term, i.e., the period of construction. our recent findings indicate that highway investment has long term impacts in rural areas that can use the better roads to improve access of farm products to markets, and access of tourists to the area.

The distributional nature of the effects is evident when analyzing the different parts of the state. In particular, while certain counties are likely to gain from improved roads, others are likely to lose and the statewide effect is not significant; in addition, the statewide effect is very small in size, i.e., over ten years an extra $\$ 1$ million would create an average of only 5-8 new jobs statewide. The negligible economic effect of highway funding on a statewide basis indicates that, except in special cases. the potential for statewide economic gains could not be a valid argument on which to base decisions for increased state trunk highway funding in Minnesota.

Along the opposite causal direction, we found that the influence of total employment on highway investment is highly significant statewide. In addition, the sensitivity of highway investment relative to changes in employment is 

interpreting the findings, consistent sign patterns from the time-series equations are important in accepting the results from causality tests.

Table 1. Long-term effects of highway on employment by sector Total Service Retail Wholesale Manufacturing FIRE TCPU Agriculture

\begin{tabular}{|c|c|c|c|c|c|c|c|}
\hline State & + & + & + & + & + & + & + \\
\hline Reg Ctr & +18 & +108 & +58 & + & + & + & + \\
\hline Next $R C$ & - & & & & & & \\
\hline Urban & + & + & + & + & + & + & + \\
\hline Next U & - & - & - & - & - & - & \\
\hline Rural & +108 & & & +1 & & & \\
\hline
\end{tabular}

Table 2. Long-term effects of employment by sector on highway

\begin{tabular}{|c|c|c|c|c|c|c|c|c|}
\hline State & +58 & + & + & + & + & + & + & + \\
\hline $\operatorname{Reg} C$ tr & + & + & - & + & + & + & + & - \\
\hline Next RC & + & + & + & + & & +18 & + & +58 \\
\hline Urban & + & + & + & + & + & + & + & + \\
\hline Next U & & & - & - & & - & + & + \\
\hline Rural & +58 & + & + & - & & & + & \\
\hline
\end{tabular}

FIRE = Finance, Insurance, and Real Estate

TCPU = Transportation, Communications, and Public Utilities

Additional understanding of the role of economic indicators in highway funding decisions can be gained by analyzing the Mn/DOT highway program selection process. We performed such an analysis and developed a cost/benefit methodology to aid the highway programming decisions -. with an application to spring load restrictions and the forest industry in Northeast Minnesota.

\section{FINDINGS FROM EVALUATION OF CRITERIA FOR PROJECT SELECTION}

This section addresses the question, "What is the relationship (if any) between highway project funding decisions by the Minnesota DOT and specific indicators, including indicators that the Minnesota DOT uses?" The relative scarcity of data only allows cross-sectional analysis, which we criticized earlier. Therefore, results are correlative, i.e., they may indicate a relation between $X$ and $Y$ but cannot specify whether $X$ precedes $Y$ or not.

From the 1985 Mn/DOT project selection data in Major Construction, Reconstruction, Reconditioning, and Resurfacing, this analysis determines the major factors correlated with the decision, "to fund or not to fund" a candidate project; the factors include the selection criteria ("point system") now followed by the Minnesota DOT. The major conclusions indicate:

- The actual relationship between funding decisions and major criteria used to make the decisions is close to the relationship stated by the Minnesota DOT.

- Of all point components, Cost Efficiency (CE) and Sufficiency Rating (SR) points are most significant in Major Construction and Reconstruction, while Condition Rating (CR) is most significant in Reconditioning and Resurfacing. Goods Movements (GM) and PM (Peak Month) points are not significant. 

Because a regional highway network serves several plants and markets and consists of a large number of links, the benefits resulting from improving a single link of the network are almost never immediately realized. In the case of weight limits, a benefit is realized only when the minimum load limit along a travel route is raised. We apply our analysis to transportation data from the forest industries and the highway system in northeast Minnesota. In analyzing the economic viability of upgrading spring weight restrictions on the state highways of that region, we solve the problem of maximizing the realizable benefits, resulting from the alleviation of weight restrictions or other road improvements, while minimizing incurred construction costs. Benefits and costs are amortized over the time horizon appropriate for each project. The total net benefit is summed over all customers and commodities subject to the available budget over the planning horizon. The algorithm considers two maintenance policy alternatives, (a) a road is upgraded to carry heavier loads or (b) a road is not upgraded but is still used for heavier loads, leading to reduced expected life and an increase in maintenance costs. The set of all feasible projects includes upgrading combinations that lead to the same final outcome but are accomplished in a different sequence. For instance, a 9-ton road may be upgraded to 10-ton directly; alternatively, the 9-ton road may be partially improved at first, e.g., to 10 -ton for 10 months.

Our case study focuses on the paper and waferboard product industries of NE Minnesota. Direct benefits would accrue if the network upgrading reduced transportation costs and, thus, made the final production cost of the above forest products more competitive in the nation's markets. As the responses to our industry survey indicated, these industries could, then, increase the production capacity of their plants and, in time, their export market share in the national and international markets. Based on our survey and Mn/DOT data on the principal highways the forest industries use in northeast Minnesota, the highways were segmented into links by load category and estimated remaining life. Our algorithm was then used to prioritize these projects subject to a budget constraint. Based on the algorithm, only the segment of Trunk Highway 33 ( $\mathrm{TH}$ 33), connecting Interstate 35 ( $\mathrm{I}-35$ ) with Cloquet has a benefit/cost ratio greater than 1 . From all candidate upgrading projects considered, the following top 5 were selected in order of priority:

1. TH 33 , from I-35 to Cloquet; upgrade to 10 -ton road year round.

2. TH 33, from Cloquet to TH 2; and

TH 2, from TH 33 to Grand Rapids; to 10-ton year round.

3. TH 53, Cook to International Falls; to 10-ton for 10 months.

4. TH 2, Grand Rapids to Bemidji; to 10 -ton year round.

5. TH 61, Two Harbors to U.S. border; to 10 -ton for 10 months or year round.

[The Minnesota DOT has recently alleviated weight restrictions on $T H 2$ based on highway engineering criteria (deflection tests) and is considering upgrading $T H$ 33 from I-35 to Cloquet.]

As part of the case study, we have also used an alternative indirect analytical method to assess the economic effects of a transportation policy in Northeast Minnesota. In particular, we use the Input-Output SIMLAB economic simulation model to assess the possible economic effects on the local forest industry of increasing all spring load restrictions in NE Minnesota to 10 tons year round. The timber industry sectors considered include logging, sawmills, particle 

4. Strong evidence of favorable long-term employment effects of highway improvements in rural areas was found for the wholesale sector. However, this long-term effect does not last more than 8 years following the highway expenditures. Strong evidence of favorable long-term effects was also found in rural areas that either have a strong natural resource base, e.g., tourism, or can benefit from improved access of their farm products to markets; although such effects would involve few jobs, they could still be important to the local economy. Favorable effects in other sectors of the rural areas were found only in the short term, and most would be construction-related. Therefore, if government policy is to stimulate employment in rural areas, it can accomplish this during the construction of highways. If policy is to achieve long-term improvements, government can improve transportation to achieve this in some sectors: however, in most cases, transportation improvements would have to be accompanied by additional development policies.

5. Highway funding alone cannot stimulate Minnesota agriculture.

6. The current Minnesota DOT project selection process is highly responsive to the recommendations of the individual districts. District recommendation (reflecting, among other factors, current economic conditions) contributes to the process as much as all other selection factors combined. As long as the Minnesota DOT plans to continue to place such a substantial weight on the district recommendation. there is no need to use additional economic criteria. (This conclusion has been drawn from limited but fairly typical data.)

7. Our time-series analysis indicates that the Minnesota DOT is highly responsive to the economic conditions of Minnesota in two ways: First, in most cases the DOT plays a strongly passive, reactive role by increasing highway investment where the economy is improving -- a role that is largely effective. Second, in certain rural counties the DOT plays a stimulative role by providing more funding when their economy is faultering -- a role that is, for the most part, not as effective. In particular, although the evidence indicates that increased highway investment is most effective in favorably influencing the economy of the regional centers of the state and of certain natural-resource and farm-product based rural counties, it is the economic conditions of all rural areas that exert the most significant influence on Minnesota DOT highway funding decisions. It can be inferred that, unless the state's development priorities are to be changed, inclusion of additional economic criteria in the Minnesota DOT highway project selection process is not needed.

8. If the state's priorities are that the economies of the regional centers should not be improved at the expense of the outlying economies, the evidence indicates no need to use additional economic indicators as criteria in highway programming. The political climate in Minnesota, with a thriving economy in the economic centers and a depressed economy in many areas of Greater Minnesota, is to encourage economic development outside the centers. Our analysis indicates that any attempt to further improve the employment of the centers by improving transportation may also have undesirable employment effects on their neighbors. To be sure, such effects would be tempered by the income increase of the residents in the adjacent areas, who can use the 